\title{
Human stanniocalcin-2 exhibits potent growth-suppressive properties in transgenic mice independently of growth hormone and IGFs
}

\author{
Anthony D. Gagliardi, ${ }^{2,4}$ Evan Y. W. Kuo, ${ }^{2,4}$ Sanda Raulic, ${ }^{2,4}$ \\ Graham F. Wagner, ${ }^{3}$ and Gabriel E. DiMattia ${ }^{1,2,4}$ \\ Departments of ${ }^{1}$ Oncology, ${ }^{2}$ Biochemistry, and ${ }^{3}$ Physiology and Pharmacology, Faculty of Medicine and Dentistry, \\ University of Western Ontario, and ${ }^{4}$ London Regional Cancer Centre, London, Ontario, Canada
}

Submitted 22 June 2004; accepted in final form 9 September 2004

\begin{abstract}
Gagliardi, Anthony D., Evan Y. W. Kuo, Sanda Raulic, Graham F. Wagner, and Gabriel E. DiMattia. Human stanniocalcin-2 exhibits potent growth-suppressive properties in transgenic mice independently of growth hormone and IGFs. Am J Physiol Endocrinol Metab 288: E92-E105, 2005. First published September 14, 2004; doi:10.1152/ajpendo.00268.2004.-Stanniocalcin (STC)-2 was discovered by its primary amino acid sequence identity to the hormone STC-1. The function of STC-2 has not been examined; thus we generated two lines of transgenic mice overexpressing human (h)STC-2 to gain insight into its potential functions through identification of overt phenotypes. Analysis of mouse Stc2 gene expression indicates that, unlike Stc1, it is not highly expressed during development but exhibits overlapping expression with $S t c 1$ in adult mice, with heart and skeletal muscle exhibiting highest steady-state levels of Stc2 mRNA. Constitutive overexpression of hSTC-2 resulted in pre- and postnatal growth restriction as early as embryonic day 12.5 , progressing such that mature hSTC-2-transgenic mice are $\sim 45 \%$ smaller than wild-type littermates. hSTC-2 overexpression is sometimes lethal; we observed 26-34\% neonatal morbidity without obvious dysmorphology. hSTC-2-induced growth retardation is associated with developmental delay, most notably cranial suture formation. Organ allometry studies show that hSTC-2-induced dwarfism is associated with testicular organomegaly and a significant reduction in skeletal muscle mass likely contributing to the dwarf phenotype. hSTC-2-transgenic mice are also hyperphagic, but this does not result in obesity. Serum $\mathrm{Ca}^{2+}$ and $\mathrm{PO}_{4}$ were unchanged in hSTC-2-transgenic mice, although STC-1 can regulate intra- and extracellular $\mathrm{Ca}^{2+}$ in mammals. Interestingly, severe growth retardation induced by hSTC-2 is not associated with a decrease in GH or IGF expression. Consequently, similar to STC-1, STC-2 can act as a potent growth inhibitor and reduce intramembranous and endochondral bone development and skeletal muscle growth, implying that these tissues are specific physiological targets of stanniocalcins.

stanniocalcins; stanniocalcin-related protein; development
\end{abstract}

STANNIOCALCINS REPRESENT a small family of secreted homodimeric glycoprotein hormones consisting of STC-1 and STC-2, also known as stanniocalcin-related protein (STCrP), that has been conserved from aquatic to terrestrial vertebrates. STC-1 and STC-2 do not show significant homology to any other known proteins, and this has hampered understanding of their function(s). Initially, it was assumed that mammalian STC-1 would mimic the function of fish STC-1 in mineral homeostasis, and there is evidence to support this $(26,37,52)$. Recently, however, it has become clear that STC-1 has a significantly expanded role in mammals on the basis of its

Address for reprint requests and other correspondence: G. E. DiMattia, London Regional Cancer Center, 790 Commissioners Rd., London, Ontario, Canada N6A 4L6 (E-mail: dimattia@uwo.ca). expression pattern (7), gain-of-function transgenic mouse studies $(13,49)$, and subcellular localization $(29,38)$.

STC-2 was initially identified as a stanniocalcin by virtue of its $50 \%$ identity and $73 \%$ amino acid homology to a stretch of 76 amino acids located between positions 24 and 101 of human (h)STC-1 $(8,12,18,32)$. hSTC-2 amino acid sequence downstream of position 101 shows less identity (23\%) to hSTC-1, and it is 45 amino acids larger even though the genes encoding these proteins have identical intron/exon junctions (18). Unlike with STC-1, studies examining the function of STC-2 have not been reported. It is tempting to assume that the function(s) of STC-1 and STC-2 overlaps because of the similarity in primary amino acid sequence and conservation of the cysteine residues found in hSTC-1, such that hSTC-2 probably exists in the native state as a disulfide-linked dimer, as does hSTC-1 (32). However, there are distinct differences between these proteins, including the fact that STC-2 is 55 amino acids larger, most of which is present in the form of a histidine-rich $\mathrm{COOH}$-terminal region (32). With regard to expression patterns in the mouse, STC-1 appears ubiquitous but is most highly expressed during development and in the adult ovary, with significantly lower levels in other adult tissues $(7,50)$. The mouse (m)STC-2 expression pattern is unclear because different reports do not agree on STC-2 mRNA size $(8,18)$. Our preliminary studies indicate that, unlike STC-1, STC-2 is not detectable in mouse embryo tissue RNA by Northern blotting. Collectively, these data suggest that the biological role(s) of STC-2 in mammals may differ from that of STC-1, and this is further supported by the fact that STC-2 is unable to displace STC-1 from its putative receptor $(24,29)$.

It is clear that STC-1 functions as an anti-hypercalcemic hormone in fish (51). A number of studies have focused on where and when mammalian STC-1 is produced and make inferences regarding its function on the basis of localization data, but relatively few studies have directly assessed the function of STC-1 (7). There is good evidence for a role for STC-1 in mammalian mineral metabolism because it can significantly decrease renal phosphate excretion $(37,52)$, decrease intestinal $\mathrm{Ca}^{2+}$ uptake, and concomitantly increase $\mathrm{PO}_{4}$ reabsorption (26) and result in significantly higher serum $\mathrm{PO}_{4}$ levels in hSTC-1 gain-of-function transgenic mice (49). There is also data supporting a role for STC-1 control of intracellular $\mathrm{Ca}^{2+}$ in rat cardiomyocytes (41) and neuronal cells (61). These studies suggest that the action of STC-1 in directly regulating mammalian $\mathrm{Ca}^{2+}$ levels may

The costs of publication of this article were defrayed in part by the payment of page charges. The article must therefore be hereby marked "advertisement" in accordance with 18 U.S.C. Section 1734 solely to indicate this fact. 
lie primarily on intracellular pools rather than systemic $\mathrm{Ca}^{2+}$ regulation.

We and others have attempted to gain further insight into the function(s) of STC-1 through the generation of gain-of-function transgenic mice $(13,49)$. It was anticipated that overexpression of STC-1 would result in a deleterious phenotype(s) that would point to specific organ systems particularly sensitive to STC-1 signaling and therein provide the basis for further study of STC-1 action in a specific cell type. This approach was predicated on the fact that STC-1 is not detectable in serum, other than during pregnancy in the mouse (11). Our studies (49) indicated that ubiquitous overexpression of hSTC-1 results in permanent and severe postnatal dwarfism, with transgenic mice achieving body weights $30-45 \%$ less than their wild-type counterparts. Using a similar hSTC-1transgenic mouse model, others (13) observed a less severe dwarf phenotype along with decreased bone formation and somewhat altered bone structure. Congruent with a role for STC-1 in bone formation, a recent study (59) showed that it can stimulate the differentiation of rat calvaria cell cultures, implying that STC-1 is an autocrine/paracrine modulator of osteoblast development. These studies strongly suggest that STC-1 signaling can affect multiple organ systems and that it is a regulator of organ development with potent growth inhibitory properties when present in excess.

Because it is increasingly clear that STC-1 plays important physiological roles in mammals, we postulate that a related protein, STC-2, has an equally important function(s) in mammals. Given the distinct biochemical and gene expression pattern differences between STC-1 and STC-2, we chose mouse transgenesis to determine whether STC- 2 could regulate physiological pathways separate from those controlled by STC-1 and thus produce unique phenotypes. Our data indicate that STC-2 mRNA levels are markedly lower than those of STC-1 during mouse development and that it is most highly expressed in heart followed by skeletal muscle, uterus, and prostate. We have generated transgenic mice that ectopically produce hSTC-2 early in development, when it is not normally expressed, and throughout adulthood. Here, we describe that STC-2 can cause early intrauterine growth restriction, developmental delay, and severe postnatal growth retardation with disproportional organ growth. This growth inhibition appears to be independent of the growth hormone and IGF-I and -II growth regulatory pathway. These results are the first to show that STC-2 can, in an overexpression model, induce physiological effects similar to STC-1, resulting in similar but more severe phenotypes.

\section{MATERIALS AND METHODS}

Generation of hSTC-2-transgenic mice. The hSTC-2 transgene was constructed by ligation of a 1,247-bp hSTC-2 cDNA fragment from expressed sequence tag (EST) H98185 (Genome Systems, St. Louis, MO) encompassing the 909-bp coding sequence into the XhoI site of the previously described pCAGGS expression vector (34). Expression of the transgene is controlled by the bipartite promoter, consisting of the 384-bp cytomegalovirus immediate early (IE) enhancer fused to the 284-bp chicken $\beta$-actin promoter contiguous with 83 bp of the chicken $\beta$-actin 5 -untranslated sequence (UTR), followed by the 917-bp chicken $\beta$-actin intron 1 . The XhoI cloning site is located in the rabbit $\beta$-globin $3^{\prime}$-UTR of the expression cassette. The expected size of the transgene-derived hSTC-2 transcript is $\sim 1.8 \mathrm{~kb}$, and it is easily distinguishable by Northern analysis from the $\sim 4-\mathrm{kb}$ primary endogenous mSTC-2 mRNA. The pCAGGS/hSTC-2-transgenic mice were generated in the Transgenic and Gene Targeting Facility of the London Regional Cancer Centre by microinjection of purified transgene DNA into the pronuclei of fertilized C57BL/6 $\times$ CBA oocytes, as previously described (4). Transgenic founder mice were identified and genotyped by dot-blot hybridization with genomic DNA from tail biopsies and a radiolabeled 634-bp PstI/StyI hSTC-2 cDNA fragment encompassing $617 \mathrm{bp}$ of the coding sequence and $17 \mathrm{bp}$ of $3^{\prime}$-UTR (49). Southern blot analysis was performed with hSTC-2-transgenic mouse genomic DNA isolated from adult kidney to confirm intact integration of the transgene. hSTC-2- and hSTC-1-transgenic mouse lines were maintained on a C57BL/ $6 \times$ CBA background. All studies were performed with mice hemizygous for the pCAGGS/hSTC-2 transgene. Mice were housed and used in accordance with protocols approved by the University Council on Animal Care at the University of Western Ontario.

Serum hSTC-2 determination and blood chemistry. Antibodies to hSTC- 2 were prepared in rabbits after three monthly immunizations, each of $200 \mu \mathrm{g}$ of Chinese hamster ovary cell-expressed recombinant hSTC-2 dissolved in Freund's adjuvant in saline (1:1, vol/vol). Whole blood was taken from transgenic and wild-type mice immediately after $\mathrm{CO}_{2}$ asphyxiation by opening the abdomen and collecting blood, using a 25-gauge needle, from the caudal vena cava. Blood was allowed to coagulate at room temperature, and serum was collected as the supernatant from two consecutive $18^{\circ} \mathrm{C} 20$-min centrifugations at $15,000 \mathrm{~g}$. Mouse serum hSTC-2 was characterized by separating $3 \mu \mathrm{l}$ of a 1:10 dilution or $1 \mu \mathrm{l}$ of serum proteins by SDS-PAGE in 12\% gels. These gels were Western blotted with the use of a 1:5,000 dilution of rabbit anti-hSTC-2 antiserum raised by Veterinary Services, University of Western Ontario, against recombinant hSTC-2 provided by Human Genome Sciences (Rockville, MD) (60). The apparent molecular weight of transgene-derived hSTC-2 was compared with $\mathrm{hSTC}-2$ produced by the MCF-7 human breast carcinoma cell line by Western blotting. MCF-7 cells were cultured under serum-free conditions for 3 days, and the conditioned medium was collected and concentrated sixfold with Centricon YM-10 centrifugal filter devices (Millipore, Billerica, MA). Mouse serum IGF-I was measured with a rat IGF-I RIA (Diagnostic Systems Laboratories, Webster, TX) after acid-ethanol extraction of 50- $\mu$ l serum samples from 6-wk-old wild-type and hSTC-2-transgenic mice. Serum IGF-I measurements are presented as means \pm SE. Blood chemistry determinations $\left(\mathrm{Ca}^{2+}, \mathrm{PO}_{4}\right.$, alkaline phosphatase) were carried out with the Synchron Clinical System CX7 and LX20 (Beckman Coulter, Brea, $\mathrm{CA})$ at the London Health Sciences Center (London, Canada).

Northern blot analysis. Mice were $\mathrm{CO}_{2}$ asphyxiated, and tissues were removed and extracted in TRIzol (Life Technologies, Grand Island, NY) for the isolation of total RNA. All RNA samples were subjected to Northern blot analysis using the ${ }^{32} \mathrm{P}$ random primerlabeled 634-bp hSTC-2 cDNA fragment described above (50). Total RNA was pooled from three to five animals or embryos for transgene or endogenous mSTC-2 expression studies. Total RNA, isolated from 5-10 pooled male pituitaries, was blotted and hybridized with a mouse growth hormone (GH) cDNA fragment. IGF-II mRNA levels were assessed by blotting pooled total RNA from three to five embryos at embryonic day $(E) 14.5, E 16.5$, and E18.5 and hybridization with a mouse IGF-II cDNA fragment. Pooled liver total RNA from three to five mice aged 5, 10, and 15 days was blotted and hybridized with a rat IGF-I cDNA fragment to determine postnatal IGF-I mRNA levels. To normalize for RNA loading and to determine fold changes in steady-state mRNA levels, blots were hybridized to $18 \mathrm{~S}$ ribosomal DNA, and the signal was quantified using PhosphorImager and ImageQuant software (Amersham Biosciences, Piscataway, NJ).

Major urinary protein analysis. Urine was collected from agematched hSTC-2-transgenic and wild-type mice, and $2 \mu \mathrm{l}$ of urine were analyzed by SDS-PAGE in $12 \%$ gels, which were then stained with Coomassie blue. 
Analysis of hSTC-2-transgenic and wild-type mouse weight gain. Growth studies were conducted on each hSTC-2-transgenic line with wild-type littermates as controls. Hemizygous transgenic male mice were bred with wild-type females to generate timed-pregnant females carrying mixed litters of wild-type and transgenic pups. Embryos were harvested at E12.5,E14.5,E16.5, and E18.5 and dissected from the conceptus, and amniotic fluid was removed by blotting on paper towels. Wet weights were recorded, and the embryos were genotyped as described above using a portion of the embryo for DNA isolation. Human STC-1-transgenic embryo weights were determined similarly, except that wild-type females were bred to homozygous hSTC-1transgenic males from lines 2 and $1 A$ to generate litters of hemizygous transgenic embryos, and wild-type embryo weights were obtained from wild-type crosses. For postnatal growth studies, pups were numbered at birth with a surgical marker and weighed between 8:00 and 10:00 AM on postnatal day $(P) 1-P 17$ and P20, P21, P25, P30, and $P 45$. Toes were clipped on $P 10$, and numbered ear tags were applied on $P 21$ to track the mice. Mice were weaned at 21 days of age and transferred to separate wild-type and transgenic mouse stock cages for the remainder of the study period. For line 314 (L314), 25 transgenic females and 30 transgenic males were followed, and for line 372 (L372), 40 transgenic females and 39 transgenic males were included in the growth study. Seventy wild-type males and an equivalent number of wild-type females were used in this study. The growth study was extended to 80 days for $L 314$ hSTC-2-transgenic mice only.

Neonatal morbidity. New litters were carefully monitored from four different matings: hemizygous hSTC-2 matings were established within each transgenic line to produce pregnant transgenic females; wild-type C57BL/6 $\times$ CBA females were mated with hemizygous hSTC-2-transgenic males from L314, and hemizygous L314 transgenic females were mated with wild-type C57BL/6 $\times$ CBA males. Pregnant females were housed individually and monitored twice daily for the presence of a new litter; subsequently, each litter was monitored to harvest dead pups for genotyping. To determine whether hSTC-2-transgenic neonate morbidity was linked to nursing competition with wild-type neonates, another study was established in which hemizygous transgenic females from both lines and C57BL/6 $\times$ CBA females were mated with hemizygous transgenic males from both lines. Pregnant females were housed individually and monitored as described above. When litters were discovered, wild-type pups $(\sim 1.4$ g) were distinguished from transgenic pups $(\sim 1 \mathrm{~g})$ by their weight and eliminated from the litter. The average transgenic litter size was 3.8 for each line, and 25 litters were followed from L372 and 27 from L314. Litters were monitored daily, and dead pups were retrieved for genotyping to confirm transgenic status.

Organ allometry. Fourteen-week-old wild-type and L314 hSTC-2transgenic male mice were $\mathrm{CO}_{2}$ asphyxiated and weighed, and external body dimensions (nose-to-tail tip, nose-to-anus, and anus-to-tail lengths) were determined, followed by the removal of the internal organs for wet weight measurements. Organs were weighed on a Mettler PB303 DeltaRange balance immediately upon dissection, with the exception of the heart and lungs, which were briefly blotted on paper towel to remove excess blood. The remaining viscera were removed, briefly blotted dry, and weighed, and then the remaining carcass was weighed. Weighing both the anterior and posterior muscle groups of the hindlimbs and combining the weights of the left and right leg muscles determined the muscle weights of 12-wk-old animals. Tail weight for each animal was also determined after dissection from the body at the base of the tail. Organ and muscle weights were normalized to the intact body weight of the mouse and expressed as a relative percentage of body weight. This was done because a comparison of raw measurements between wild-type and transgenic mice was not feasible, given that the transgenic animals were dwarves. For the weight-matched wild-type mouse organ analysis, 26-day-old wildtype males were used because their body weight most closely matched that of 14-wk-old hSTC-2-transgenic males. Organs were dissected and weighed as described above. The dry weight of testes harvested from hSTC-2-transgenic and age-matched wild-type animals was obtained by placing pairs of testes from each animal in glass drying dishes and first obtaining wet weight. Testes were then incubated at $65^{\circ} \mathrm{C}$ until weights were constant (3 days), indicating no further detectable loss of water.

To obtain an indication of the relative mass of the skeleton, 14-wk-old hSTC-2-transgenic males and females from L314 and age-matched wild-type animals were subjected to dual-energy X-ray absorptiometry (DEXA) using a PIXI-mus Small Animal Densitometer (Lunar, Madison, WI). This analysis was performed at the Centre for Modeling Human Disease Physiology Core at the Samuel Lunenfeld Research Institute, Mount Sinai Hospital, Toronto, Canada. The procedure includes the mouse tail and head in the image and analysis. DEXA bone mineral content measurements show high correlation to the total ashed weight of bone $(r=0.99)(5,33)$; therefore, when normalized to body weight, DEXA provided a measurement of ashed skeletal mass derived from mineral content. The percent fat mass and lean mass of each animal were also determined using DEXA.

Analysis of mouse embryo fibroblast proliferation. To establish an in vitro model of the intrauterine growth retardation phenotype observed for transgenic embryos, we prepared mouse embryonic fibroblasts (MEFs) from E14.5 hSTC hemizygous transgenic litters and C57BL/6 $\times$ CBA wild-type litters (16). Cell number was obtained using an electronic particle counter (Beckman Coulter, Hialeah, FL), and MEFs were seeded at a density of $\sim 5 \times 10^{6}$ cells $/ \mathrm{ml}$ and allowed to attach to $175-\mathrm{cm}^{2}$ culture flasks overnight. MEFs were grown to confluency, and this was considered passage 0 . All experiments were conducted using passage 0 MEFs unless otherwise indicated. For the low-density proliferation assay, wild-type and hSTC-1-transgenic MEFs were plated at $1 \times 10^{5}$ cells $/ 25-\mathrm{cm}^{2}$ flask in triplicate. The zero time point cell number was obtained $5 \mathrm{~h}$ after the initial plating to take into consideration potential plating efficiency differences and obtain starting cell numbers based on adherent cells rather than the cell seeding number. Day 0 mean cell numbers were 61,760 and 70,380 for wild-type and transgenic cultures, respectively. Thereafter, the cell number was determined every $24 \mathrm{~h}$ over the 11-day assay. For the high-density proliferation study, MEFs were plated at $1 \times 10^{6}$ cells/10-cm dish in triplicate and assayed as described above. MEF proliferation characteristics over the study period were determined by calculating the fold change in cell number per day by dividing the total cell number on a specific day by the total cell number on the previous day. All experiments were performed with three to five different preparations of MEFs.

Assessment of cranial suture development. Skeletal preparations of newborn $P 1$ pups were prepared as previously described (28) after $\mathrm{CO}_{2}$ asphyxiation. Once the skeletons had been stained with Alcian blue and Alizarin red, the heads were removed below the base of the skull. The anterior surface of the skulls was photographed with an Olympus microscope (Olympus America, Melville, NY) equipped with a digital camera (Dage-MTI, Michigan City, IN) and Image-Pro Plus 4.5.1 computer software (MediaCybernetics, Silver Spring, MD). The magnification of all skull images was $\times 10$. The area of cranial patency, or the open area between the cranial suture edges, was determined as pixel area by tracing along the edge of the sutures enclosing the space between the skull plates using Openlab 3.1 software (Improvision, Lexington, MA).

Food intake. To compare food consumption in hSTC-2-transgenic and wild-type mice, we used 14-wk-old L314 transgenic males, 14-wk-old wild-type males, and 27-day-old wild-type males for the weight-matched comparison. Mice were housed in individual shoebox cages equipped with a pellet-feeding tube attached with a tube clip (Bio-Serv, Frenchtown, NJ). The mice were allowed to acclimatize in the cage for 2 days with ad libitum access to regular mouse chow and water. On day $O$ of the study, grain-based pellets (Bio-Serv) were loaded into the feeding tube, and the tube/food apparatus was weighed. Each morning for 7 days, the tube containing the food pellets was weighed to calculate the difference from the previous day, 
providing the amount of food eaten. Chewed pellets were removed from the tube and new pellets were added to fill the tube. The wild-type mice were weighed each morning to determine weight change during the study, and the hSTC-2-transgenic mice were weighed at the start of the study and at the end.

Statistical analysis. All statistical analyses of data were performed with the unpaired Student's $t$-test, using PRISM 3.0a (GraphPad Software, San Diego, CA). Statistical significance was assumed at $P<0.05$ for all experiments.

\section{RESULTS}

Expression pattern of STC-2 in mature wild-type mice. Our analysis of mouse embryos indicated that, unlike STC-1, STC-2 mRNA was not detectable in whole embryo RNA from E10.5 to E18.5 (data not shown). In adult mouse tissues, Stc2 gene expression was detectable as two distinct mRNA species of $\sim 4$ and $2 \mathrm{~kb}$ (Fig. 1). STC-2 mRNA appeared most abundant in heart, prostate, uterus, and skeletal muscle. Lower, but detectable, STC-2 mRNA was present in seminal vesicle, ovary, mammary gland, and white fat depots. Generally, our observations of STC-2 gene expression indicate overlap with STC-1 expression, but the level of expression for each hormone was distinct and tissue dependent. For example, we could not detect STC-2 mRNA in the mouse ovary, whereas STC-1 mRNA is readily detectable by Northern blot (data not shown).

Generation of transgenic hSTC-2 mice. hSTC-2 overexpression was achieved by use of the bipartite cytomegalovirus (CMV) IE enhancer fused to the chicken $\beta$-actin promoter (Fig. 2). Southern blotting to confirm intact integration of the transgene revealed that two independent lines of transgenic mice were successfully created, L314 and L372 (data not shown). Both founders stably transmitted the transgene to progeny, thereby establishing two independent lines of hSTC2-transgenic mice.

hSTC-2 transgene expression is widespread. Our first objective was to determine the pattern of hSTC-2 transgene expression and whether hSTC-2 was detectable in the serum of transgenic mice. Transgene expression was detectable by Northern blotting of whole embryo RNAs from E10.5 onward in both lines of mice, whereas no signal was observed in the wild-type embryo (Fig. 3A). Northern blotting of adult transgenic tissue RNAs from both lines indicated that all tissues tested contained the expected $\sim 2-\mathrm{kb}$ mRNA corresponding to the transgene-derived hSTC-2 transcript (Fig. 3, B-D). The highest levels of transgene expression were seen in the heart and skeletal muscles of both lines of hSTC-2-transgenic mice. Moreover, an analysis of transgene expression between the sexes in either line did not reveal a sex-specific difference (Fig. $3, B$ and $C$ ), as seen previously for hSTC-1-transgenic mice (49).

The antisera raised to hSTC-2 was characterized by Western blotting, using conditioned medium from human cell lines (Fig.
$4 A)$. The predicted and observed molecular mass of the mature secreted form of hSTC-2 is $\sim 30.6 \mathrm{kDa}$ (32). A major band of $\sim 33 \mathrm{kDa}$ and two larger minor bands were seen in concentrated conditioned media from the human MCF-7 breast carcinoma cell line and not from HeLa cells, which corroborates our Northern analysis of hSTC-2 gene expression in these cell lines. The antisera detected hSTC- 2 in conditioned media from the rat GC pituitary tumor cell line, indicative of its ability to cross-react with rodent STC-2 (Fig. 4A), but did not detect STC-2 in wild-type mouse serum as we have reported previously for STC-1 (11). However, in transgenic mouse serum, the antiserum revealed 31- and 35-kDa hSTC-2 bands, possibly due to different posttranslational modifications (Fig. 4B). By Western blot analysis, L314 serum contained approximately fivefold more circulating hSTC-2 than that of L372 (Fig. 4B).

hSTC-2-transgenic neonate viability is significantly reduced. While breeding the hSTC-2-transgenic mouse lines, it was clear that a large number of transgenic pups were lost soon after birth. Hemizygous transgenic males were bred with wildtype and hemizygous transgenic females to determine whether neonatal morbidity was associated with transgene homozygosity in both lines. Regardless of the mating genotypes, neonate morbidity ranged from 26 to $33.8 \%$ within the first few days of life (Table 1), indicating that neonatal death was not dependent on transgene homozygosity. Importantly, this was the first indication that excess production of a stanniocalcin could cause death. Moreover, the death of transgenic neonates was not due to an inability to compete with wild-type pups for breast milk, as the removal of wild-type pups from mixed litters did not alter neonatal morbidity (31.3\% for $L 314$ and $28.4 \%$ for $L 372$ ).

Overexpression of stanniocalcins causes intrauterine growth restriction and postnatal growth retardation. This overt phenotype was first noticed in $P 1$ pups; therefore, we examined embryo weights from E12.5 to E18.5 to determine whether hSTC-2 caused intrauterine growth restriction. The weights of hSTC-2-transgenic embryos were significantly less than wild-type embryos from E12.5 onward (Table 2). The difference in embryo size can easily be seen in the images of representative embryos and is evident as early as E10.5 (Fig. 5).

In a previous study with $\mathrm{hSTC}-1$ transgenic-overexpressing mice (49), we also observed postnatal growth restriction. Therefore, in this study, we reassessed the growth of transgenic embryos from hSTC-1-transgenic lines $1 A$ and 2 for intrauterine growth restriction. In the lower-expressing line $1 A$, significantly smaller embryos were first detected at E14.5, and at E13.5 for line 2. Therefore, both stanniocalcins had similar growth inhibitory effects on embryonic growth that correlated with the onset of transgene activation.

To assess hSTC-2-induced postnatal growth restriction, we measured the body weights of wild-type and transgenic ani-

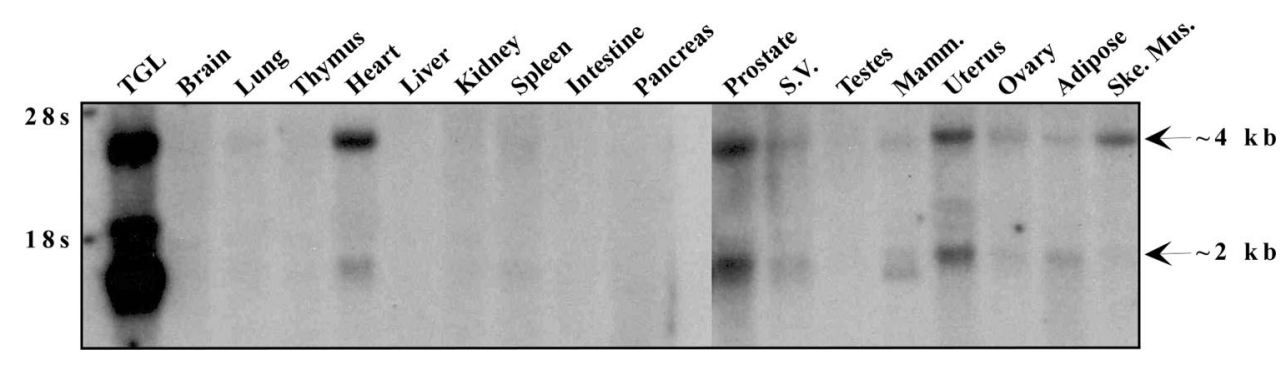

Fig. 1. Endogenous stanniocalcin (STC)-2 expression. Endogenous Stc2 gene expression was assessed in adult mouse tissues by Northern analysis. Total RNA $(50 \mu \mathrm{g})$ pooled from at least 3 wild-type mice showed 2 distinct STC-2 mRNA species of $\sim 2$ and $4 \mathrm{~kb}$. Mamm, mammary gland; Ske. Mus., skeletal muscle; S.V., seminal vesicle; TGL, mouse pituitary cell line. 


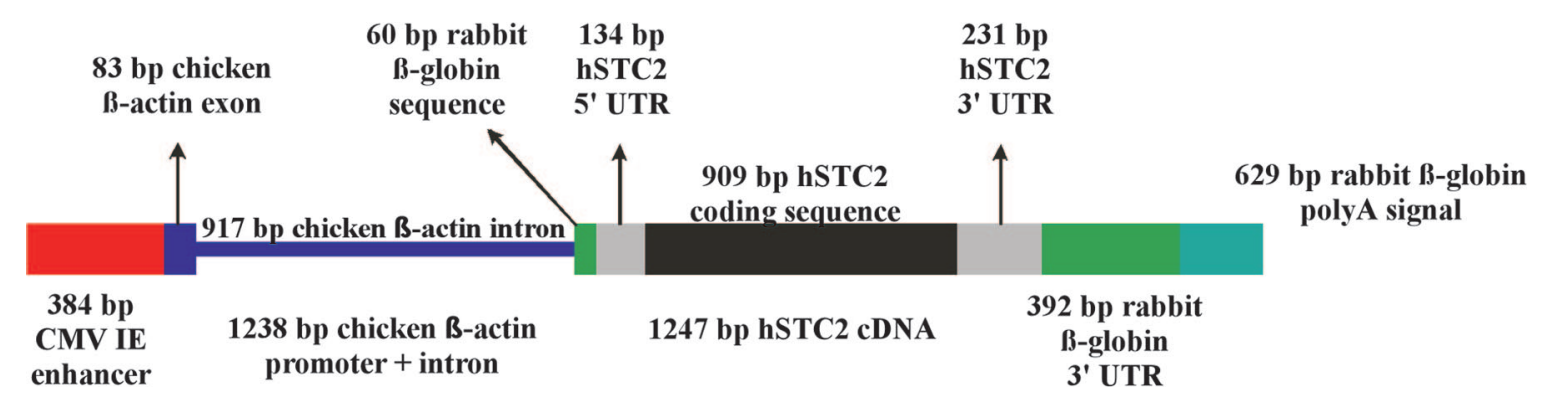

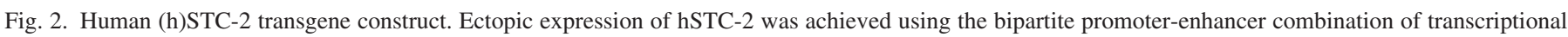

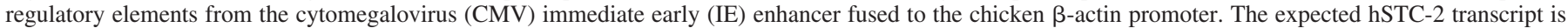
$\sim 2 \mathrm{~kb}$ and distinguishable from the major endogenous mouse $(\mathrm{m})$ STC-2 transcript of $\sim 4 \mathrm{~kb}$.

mals from both lines for a total of 45 days. Statistical analyses of the weight determinations indicated that the transgenic offspring remained significantly smaller than their wild-type littermates throughout the study (Fig. 6A). By the end of the study, the L314 and L372 transgenic females were 43.5 and $41 \%$ smaller, respectively, than their wild-type female siblings. Similarly, the transgenic males were $40.3 \%$ (L314) and 45.2\% (L372) smaller than their wild-type male littermates. The growth study was extended to 80 days for $L 314$, during which time the weight differential with wild-type littermates was maintained $(P<0.0001)$ such that transgenic males and females were 46.8 and $43.2 \%$ smaller, respectively (data not shown).

These weight measurements were then used to assess weight gain per day to determine whether the pattern of growth of hSTC-2 transgenics was distinctly different from that of wildtype littermates (Fig. 6B). Statistical analysis of the data revealed that the amount of weight gained per day by hSTC2-transgenic mice was significantly $(P=0.003)$ less than their wild-type littermates from $P 2$ to $P 15$. From $P 17$ to $P 25$, hSTC-2-transgenic pups experienced a slowdown in growth relative to their wild-type counterparts, and this corresponded to the adjustment period associated with weaning at $P 21$. From $P 17$ to $P 45$, the gap between wild-type and transgenic mice in the amount of weight gained per day increased with age and remained statistically significant $(P<0.0001)$.

Plotting the body mass data as a growth rate curve was done to determine whether the hSTC-2-transgenic mice exhibited significantly slower growth rates compared with their wildtype littermates (Fig. 6C). The transgenic mice generally exhibited a significantly slower rate of growth from $P 1$ to $P 30$; however, from $P 30$ to $P 45$, both sexes from each transgenic line displayed a higher growth rate than wild-type mice. Then, from $P 45$ to $P 52$, the growth rates of both transgenic and wild-type mice decreased to a constant rate. Interestingly, the growth rates of the wild-type and hSTC-2-transgenic mice were not significantly different from $P 45$ to $P 73$ but became different from $P 73$ to $P 80$, likely because wild-type mice gained additional weight due to fat deposition.

hSTC-2 overexpression can affect organ size. To determine whether hSTC-2 affected the growth and morphology of specific tissues, we performed organ allometry studies on 14-wkold hSTC-2 L314 males and normalized the wet organ weights to body weight for comparison with sex- and age-matched wild-type littermates. The hSTC-2-transgenic males were $45 \%$ smaller than their wild-type littermates. hSTC-2-transgenic males were significantly smaller than their age-matched wild- type counterparts in total length $(3 \mathrm{~cm})$, body length $(1.6 \mathrm{~cm})$, and tail length $(1.7 \mathrm{~cm})$ (Table 3$)$. Statistical analyses of the normalized data showed that the brain, kidney, liver, heart, lung, and viscera of hSTC-2-transgenic males comprised a larger percentage of body weight compared with age-matched wild-type males (Table 4). The largest difference in normalized organ weights was seen for hSTC-2-transgenic testes that were $72 \%$ larger than expected and essentially identical in wet weight to those from wild-type male mice. Fluid accumulation in the transgenic testes did not account for the greater-thanexpected weight, as the dry weights of transgenic and wildtype testes were 0.022 and $0.024 \mathrm{~g}$, respectively $(P=0.2961)$.

After removal of the major organs and viscera, the remaining carcass consisting of skin, muscle, and skeleton was weighed, and the normalized data indicated that the hSTC-2transgenic carcass was $8 \%$ smaller than expected $(P<0.0001)$. This small but statistically significant difference implied that the skeleton and/or skeletal muscle was negatively affected by hSTC-2 overexpression. To analyze the bone, we performed an age-matched comparison of whole skeletons from wild-type and hSTC-2-transgenic mice with DEXA. The data, when normalized to the whole body mass (43), revealed that there were no differences between wild-type and transgenic mice of both sexes, indicating that the change in carcass mass was not due to a disproportionably smaller skeleton (data not shown). However, skeletal muscle clearly showed a $15-32 \%$ reduction ( $P<0.05-0.0001)$, depending on the muscle group (Table 4$)$. This implied that the growth-restrictive effect of hSTC-2 on the whole animal was in part due to a reduction in normal muscle growth.

Organ allometry was also performed with weight-matched wild-type mice to determine whether hSTC-2-transgenic mouse body composition was equivalent to a similar-size wild-type mouse. Because of the large difference in weight between 14-wk-old wild-type and hSTC-2-transgenic mice, this study necessitated the use of 26-day-old wild-type males to provide appropriately weight-matched mice (Table 4). In terms of linear measurements, the 14-wk-old hSTCrP-transgenic males were slightly bigger $(0.53 \mathrm{~cm})$ than the weight-matched wild-types because of a difference in tail length (Table 3 ). It is notable that, despite the longer tail length, hSTC-2-transgenic tail mass was $45 \%$ less than in weight-matched wild-type males (Table 3). We found that only the lung and heart absolute weights were not statistically different between transgenic and wild-type mice. Collectively, these data suggest that hSTC-2 expression results in a growth restriction phenotype 
where a 14-wk-old transgenic male typifies a 26-day-old wildtype mouse in terms of body proportions and organ mass.

Food intake by hSTC-2-transgenic mice exceeds that of wild-type mice. It is possible that the dwarf phenotype induced by hSTC-2 expression could in part be due to a significant change in food intake. On account of their age (14 wk), the average weight of age-matched wild-type and hSTC-2-transgenic mice did not change significantly over the 7-day study period, whereas weights of the younger weight-matched wildtype mice increased by $5 \mathrm{~g}$. When food consumption was

A

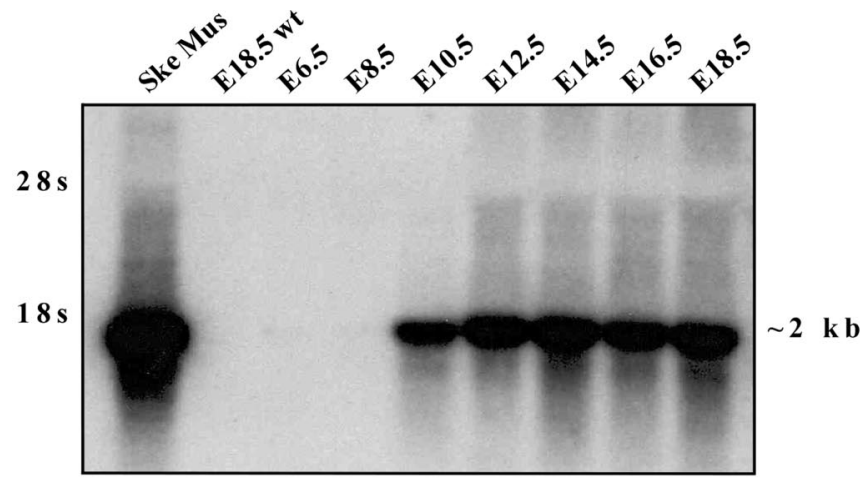

B $\frac{\text { Liver }}{F \quad M} \frac{\text { Kidney }}{F \quad M} \frac{\text { Spleen }}{F} \frac{\text { Heart }}{F \quad M} \frac{\text { Brain }}{F} \frac{\text { Ske Mus }}{\text { F Thymus }} \frac{\text { Adipose }}{\text { T }}$

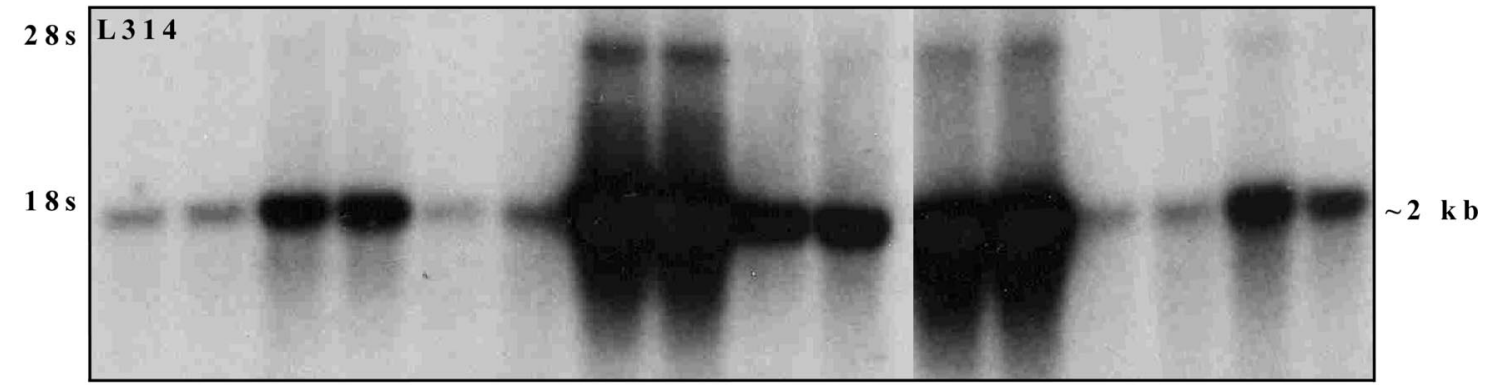

C $\frac{\text { Liver }}{M \quad F} \frac{\text { Kidney }}{M \quad F} \frac{\text { Spleen }}{M} \frac{\text { Heart }}{M} \frac{\text { Brain }}{M} \frac{\text { Ske Mus }}{M} \frac{\text { Thymus Adipose }}{M} \frac{\text { A }}{M} \frac{\text { F }}{M}$
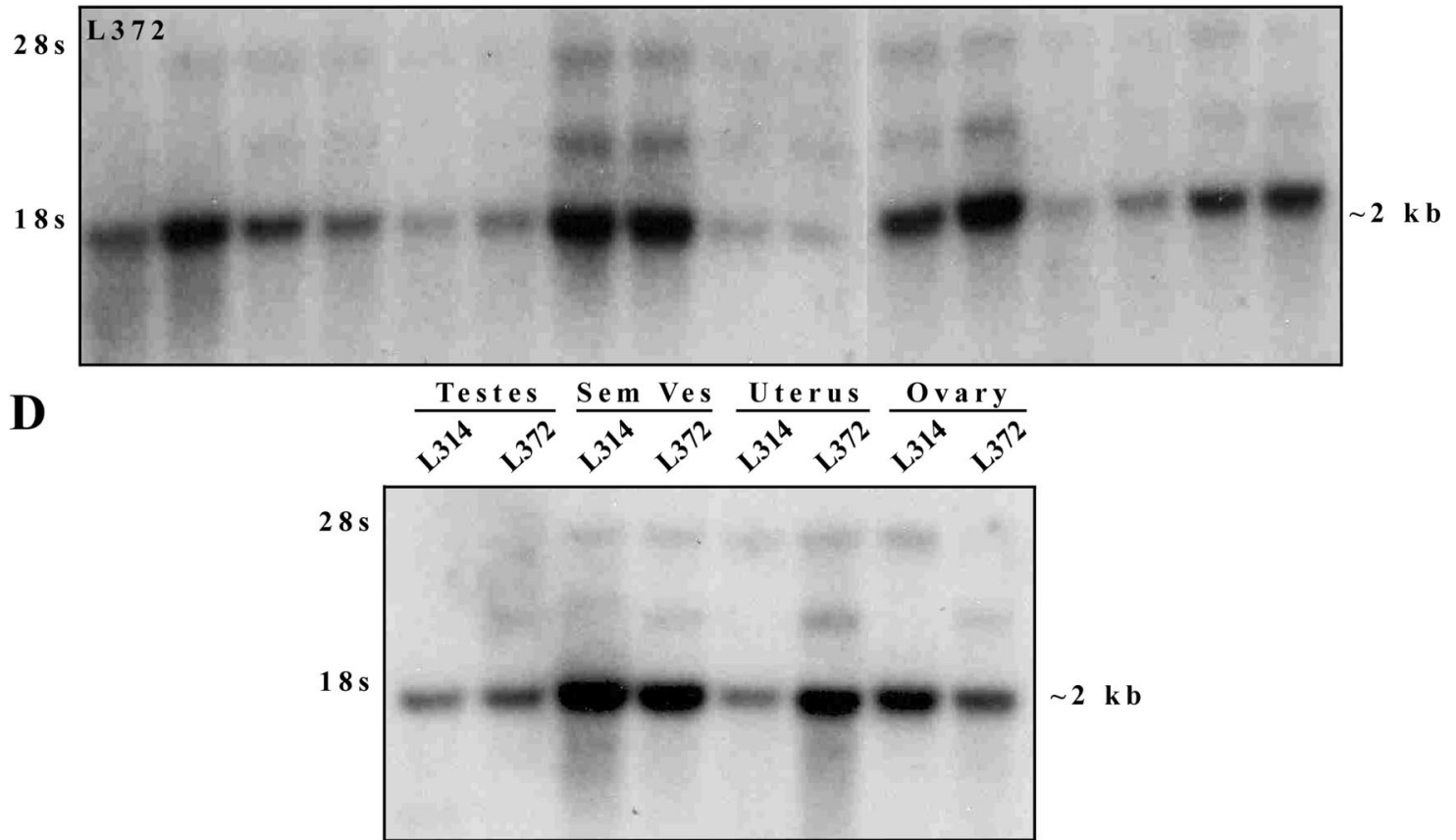

Fig. 3. hSTC-2 transgene expression. A: transgene-derived hSTC-2 transgene mRNA was detectable by Northern blotting with $50 \mu \mathrm{g}$ of whole embryo RNA, starting at embryonic day $(E) 10.5$ in both lines. $B-D$ : transgene hSTC-2 mRNA was detected in all tissues tested, with the highest levels found in the heart and skeletal muscle $(B, C)$. $L 314$ mice $(B)$ exhibited higher levels of transgene expression than $L 372$ mice $(C)$, with no apparent difference in tissue expression pattern or between the sexes after $18 \mathrm{~S}$ rRNA normalization (not shown). Total RNA (30 $\mu \mathrm{g}$ ) pooled from 3 to 5 mice was analyzed, and the autoradiograms are from 24-h exposures. M, male; F, female; wt, wild type; Sem Ves, seminal vesicle. 


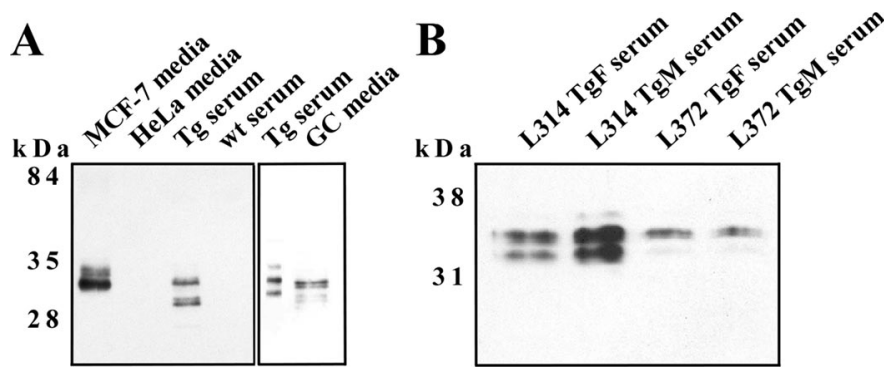

Fig. 4. Western blot analysis of cell line and transgene-derived hSTC-2 protein levels. A: hSTC-2 was detected in concentrated conditioned medium from the human MCF-7 breast carcinoma cell line but not in conditioned medium from the HeLa cells. Two immunoreactive bands were seen in hSTC-2-transgenic serum at $\sim 31$ and $35 \mathrm{kDa}$, whereas no signal was observed in wild-type mouse serum. Cross-reactivity to rodent STC-2 was demonstrated using conditioned medium from the rat GC cell line. $B$ : loading of equal volumes $(1 \mu \mathrm{l})$ of serum from $\mathrm{hSTC}$-2-transgenic mice from both lines showed that $L 314$ contained $\sim 5$-fold higher levels of hormone compared with $L 372$. $\mathrm{Tg}$, transgenic; $\mathrm{TgF}$, transgenic female; $\mathrm{TgM}$, transgenic male.

examined as a function of body weight, it was clear that hSTC-2-transgenic males ate $22 \%$ more food than their agematched wild-type counterparts $(P<0.05$; Fig. 7). This result eliminates the possibility that higher-than-normal STC-2 production led to a behavioral defect that altered food consumption and ultimately caused undernourishment and delayed growth. DEXA analysis also revealed that female and male transgenic mice on average carried 1.8 and $2.4 \%$ more fat, respectively (Table 5). The higher fat content was not statistically significant compared with wild types and may be associated with their greater rates of food intake.

$M E F$ proliferation rate and cell size. The obvious intrauterine and postnatal growth restriction induced by hSTC-1 or hSTC-2 suggested that the ectopic expression of these hormones possibly results in reduced cell proliferation, alterations in cell size, or increased cell death. To examine these mechanistic possibilities, we generated primary MEF cultures from E14.5 wild-type and hSTC-1-transgenic embryos and evaluated their growth characteristics. Growth of high-density or low-density MEF cultures was monitored over an 11-day period. We did not observe a significant difference in cell number that correlated with an altered growth rate (data not shown). Forward light scatter flow cytometry was used to determine whether the trend of reduced hSTC-1 MEF cell numbers at high density reflected an increase in cell volume, but no significant difference was detected (data not shown). An increase in cell death due to ectopic hSTC-1 expression was also not likely, because the growth characteristics of transgenic and wild-type MEFs were not significantly different. Therefore, the reduced growth potential caused by overexpression of
STCs was not replicated in vitro using embryonic mixed mesenchymal cell cultures. This suggests that the growthrestrictive phenotype is not cell autonomous but rather caused by an inherent change in developmental programming.

Intramembranous and endochondral bone formation. To assess whether the dwarfism exhibited by the overexpression of hSTC-2 manifested itself at the level of gross skeletal development, the cartilage and bones of newborn $(P l)$ mice were stained with Alizarin red and Alcian blue. On visual inspection it was strikingly apparent that the intramembranous bones of hSTC-2-transgenic neonates were less developed than the wild types (Fig. 8A). Transgenic mice exhibited severe cranial patency between the leading edge of the frontal and parietal bones compared with wild-type mice. Cranial patency area in hSTC-2-transgenic skulls was found to be 26,010 pixels compared with 12,620 pixels for wild-type skulls $(P<0.0001)$ (Fig. 8B). hSTC-1-overexpressing lines were also analyzed in this manner and found to exhibit a greater degree of cranial patency compared with wild-type mice (data not shown). With regard to endochondral bone formation, developmental delay was observed at $E 16.5$ (Fig. 8C). The ilium, ischium, and pubic bones of the hip were ossified in the wild-type embryo, whereas little or no ossification is apparent in the hSTC-2transgenic littermates (Fig 8C). Ossification is also lacking in the sacral vertebrae of the transgenic embryos.

hSTC-2 overexpression does not significantly affect serum $\mathrm{Ca}^{2+}$ and $\mathrm{PO}_{4}$. A number of reports have described effects of STC-1 on mineral metabolism $(26,37,52)$. Therefore, we sought to determine whether excess hSTC-2 significantly altered serum levels of $\mathrm{Ca}^{2+}$ and $\mathrm{PO}_{4}$. To this end, 9-wk-old hSTC-2-transgenic and wild-type sera were analyzed, and only L314 transgenic females showed a significant decrease in serum $\mathrm{Ca}^{2+}$ (Table 6). However, serum alkaline phosphatase levels were significantly lower in hSTC-2-transgenic males and females, but only for the higher expressing $L 314$ mice.

$G H$ and IGF production in hSTC-2-transgenic mice is not altered. The obvious growth restriction induced by hSTC-2 overexpression suggested that STC-2 may interfere with expression of the primary growth-promoting trophic factors, $\mathrm{GH}$, IGF-I, and IGF-II, thus accounting for the dwarf phenotype. To examine this possibility, we performed Northern analysis of steady-state GH mRNA levels in 6-wk-old males and observed no difference between transgenic and wild-type animals (Fig. $9 A$ ). It is well established that the production of major urinary proteins is dependent on a normal GH secretion pattern and signaling pathway, and alterations in the abundance of major urinary protein (MUP) in the urine is indicative of perturbed $\mathrm{GH}$ production $(2,31,35,53)$. A comparison of transgenic and wild-type mouse urinary MUP levels by SDS-PAGE (Fig. 9B)

Table 1. Neonatal morbidity

\begin{tabular}{|c|c|c|c|c|c|}
\hline Mating & \multicolumn{2}{|c|}{ No. of Pups } & \multicolumn{2}{|c|}{ No. of Neonate Deaths } & No. of Litters \\
\hline L314 het $\times$ het & $73(29.2 \%)$ & $177(70.8 \%)$ & $6(14.6 \%)$ & $60(33.8 \%)$ & 41 \\
\hline L314 TgF $\times \mathrm{wtM}$ & $91(56 \%)$ & $65(44 \%)$ & $3(3.2 \%)$ & $17(26 \%)$ & 26 \\
\hline$L 314 \mathrm{TgM} \times \mathrm{wtF}$ & $154(57.6 \%)$ & $113(42.3 \%)$ & $2(1.5 \%)$ & $28(24.45 \%)$ & 32 \\
\hline
\end{tabular}

Values in parentheses represent the resultant percentage of mice of the indicated genotype for each mating and the percentage of neonate deaths of that genotype. Tg, transgenic; wt, wild type; F, female; M, male; het, hemizygous. 
Table 2. Differences in weight between hSTC-1- and hSTC-2-transgenic and wild-type embryos

\begin{tabular}{|c|c|c|c|c|c|}
\hline & E12.5 & E13.5 & E14.5 & E16.5 & E18.5 \\
\hline hSTC-1 L2 vs. wt & $0.0(31)$ & $24.4 *(37)$ & $25.2 *(39)$ & $133.3 *(47)$ & $335.7 *(20)$ \\
\hline
\end{tabular}

Values are mean differences in embryo weights $(\mathrm{mg})$; values in parentheses are the no. of embryos weighed at each time point. hSTC, human stanniocalcin; L314, L2, and L1A, lines 314, 2, and 1A, respectively; E12.5, E13.5, E14.5, E16.5, and E18.5, embryonic days 12.5, 13.5, 14.5, 16.5, and 18.5, respectively; ND, not determined. $* P>0.001$ (Student's $t$-test).

indicated that hSTC-2 overexpression had no effect on GH signaling.

IGF-I and IGF-II mRNA levels were examined in transgenic and wild-type tissues, and serum IGF-I was measured in 6-wk-old mice to determine whether hSTC-2 overexpression caused a significant reduction in the production of these growth factors. IGF-II expression is greatest during development. As expected, steady-state IGF-II mRNA levels increased with developmental age, but a significant difference between transgenic and wild-type IGF-II mRNA abundance was not observed (Fig. 9C). Liver IGF-I gene expression was assessed during early postnatal development. As for IGF-II, we did not observe a significant change in IGF-I mRNA levels in transgenics compared with wild-type littermates (Fig. 9D). To confirm the Northern data for IGF-I expression, we measured serum IGF-I by RIA and found higher levels of circulating IGF-I in hSTC-2-transgenic male serum relative to wild-type littermates: 571.2 vs. $355.5 \mathrm{ng} / \mathrm{ml}$, respectively $(P<0.0001)$. hSTC-2-transgenic female serum IGF-I levels $(452.9 \mathrm{ng} / \mathrm{ml})$ were not different from wild-type levels $(401.2 \mathrm{ng} / \mathrm{ml})(P=$ $0.3105)$. Collectively, these data indicate that hSTC-2-induced growth restriction during development and during postnatal life is not likely due to a change in production of GH or the IGFs.

\section{DISCUSSION}

The initial objective of our study was to determine whether hSTC-2 would generate phenotypes distinct from those elicited by hSTC-1 in transgenic mice and therein suggest that these factors perform distinct functions in mammals. Our results are the first to show that hSTC-2 is bioactive in mammals and, when constitutively expressed in mice, produces a phenotype similar to that generated by hSTC-1. The primary difference was that serum $\mathrm{PO}_{4}$ and $\mathrm{Ca}^{2+}$ levels in hSTC-1-transgenic mice were significantly altered, whereas we found little evidence for such changes in hSTC-2-transgenic mice. Moreover, high neonate morbidity was caused by hSTC- 2 overexpression, whereas this was not reported for hSTC-1-transgenic mice. Collectively, the data show that STC-1 and STC-2 can exert powerful growth-suppressive effects in pre- and postnatal life.

We first determined the expression pattern for the $S t c 2$ gene because previous reports do not agree on the size of the mSTC-2 mRNA or its distribution $(8,18)$. Our Northern analysis detected $\sim 4$ - and 2-kb STC-2 mRNAs. The $\sim 4-\mathrm{kb}$ mRNA was expected because of the long $3^{\prime}$-untranslated sequence $(\sim 3.1 \mathrm{~kb})$ found in hSTC-2 and mSTC-2 EST sequences. The smaller transcript was likely due to use of alternative polyadenylation signals, because there is no evidence for a larger coding sequence among mSTC-2 EST sequences. Although the expression patterns of the stanniocalcins overlap, the abundance of each mRNA in mature mouse tissues is significantly different. For example, STC-2 is barely detectable in ovary, kidney, and whole embryo RNAs, whereas STC-1 is highly expressed in these tissues (50). This must have important implications for the tissue-specific function of these proteins because, unlike STC-1 in fish, they are not typically found in the circulation. Consequently, their specific sites of
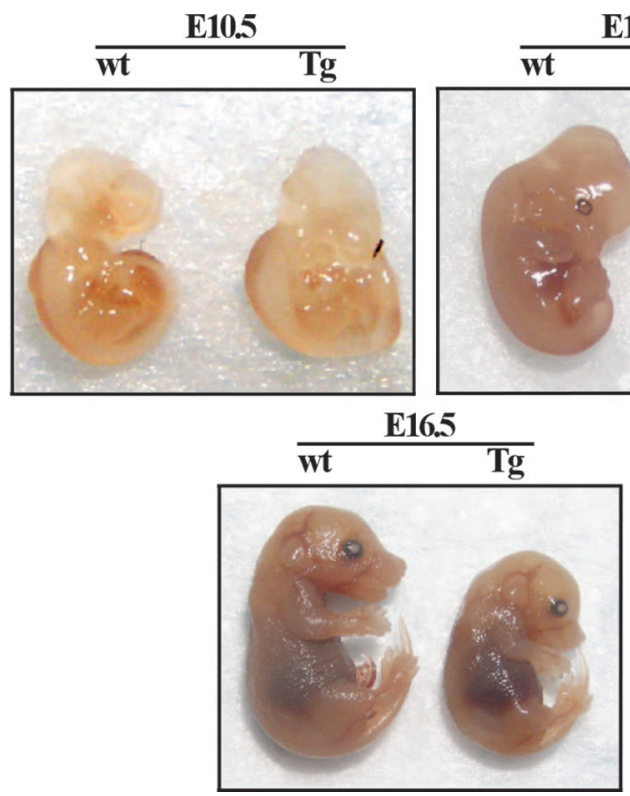

E125

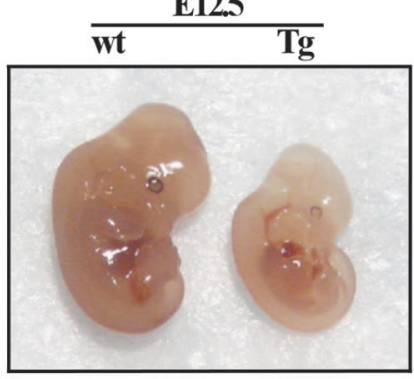

E18.5

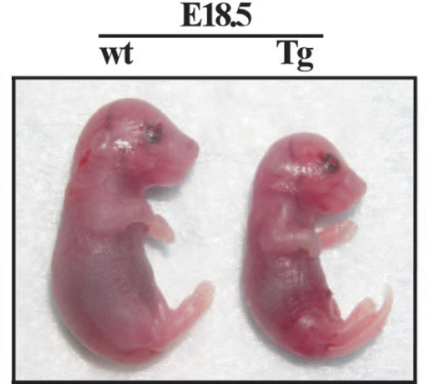

E14.5

$\overline{\text { wt } \quad \text { Tg }}$

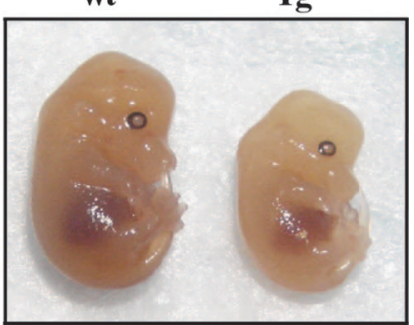

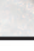

$\mathrm{Tg}$

Fig. 5. hSTC-2-transgenic embryo growth restriction. Representative images of wildtype and transgenic embryos at the indicated day of embryonic development (magnification is not the same for each image). 
A

Fig. 6. Postnatal growth restriction and changes in growth rate exhibited by $L 314$ hSTC-2 transgenic mice. A: weights of transgenic and wild-type pups were followed for 45 days after birth. Transgenic weights were significantly less than wild types on all days $(P>0.0001)$. B: weight gain/day was calculated by subtracting the weight obtained on the previous day and plotting the difference. $C$ : growth rate was determined as the percent increase in weight from the 1st day to the last day in the growth period. Black solid line, wild-type male; blue line, transgenic male; red line, wild-type females; pink line, transgenic females.

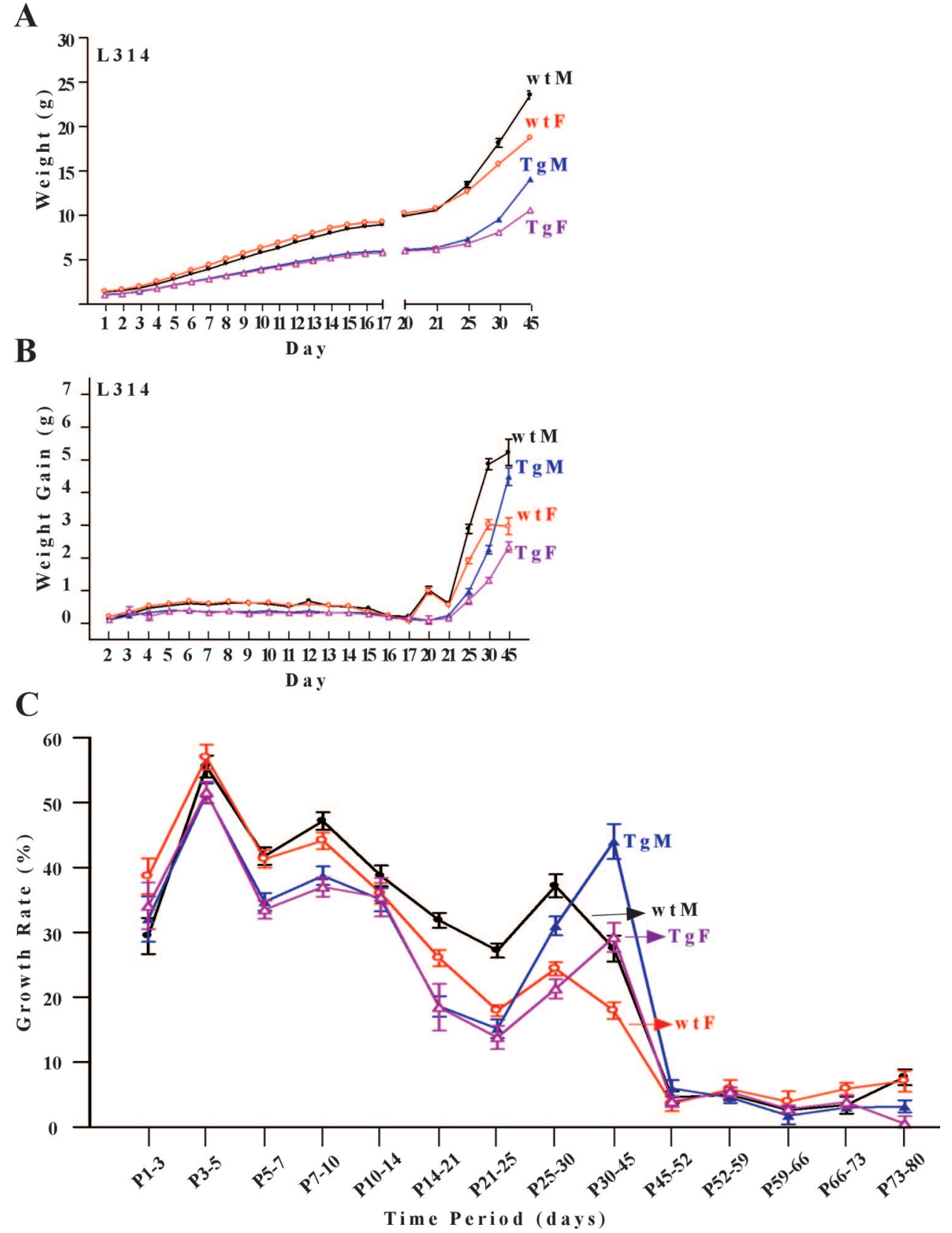

synthesis may be important determinants of their paracrine/ autocrine functions.

Among the phenotypic consequences of hSTC-2 overexpression, the first to be observed was the $\sim 30 \%$ loss of transgenic neonates in mixed litters, which clearly indicated that hSTC-2 hyperstimulation can be lethal. The physiological basis for transgenic pup mortality was not immediately evident, because transgenic pups did not manifest any obvious physical abnormalities other than being significantly smaller than their wildtype littermates. It is notable that hSTC-1-transgenic mice produced by Filvaroff et al. (13) did not exhibit transgenic neonate morbidity, even though transgene expression was specific to and high in skeletal muscle, similar to the hSTC-2transgenic mouse model described here. This obviously points

Table 3. Body and tail length comparisons

\begin{tabular}{|c|c|c|c|c|c|}
\hline & Total Length, cm & Body Length, cm & Tail Length, cm & Tail Weight, g & Tail Weight as \%Body Weight \\
\hline L314 TgM & $14.10 \pm 0.145^{*}$ & $7.778 \pm 0.07 *$ & $6.284 \pm 0.075^{*}$ & $0.2368 \pm 0.009 * \dagger$ & $1.377 \pm 0.044 * \dagger$ \\
\hline Age-matched wtM & $17.13 \pm 0.147$ & $9.383 \pm 0.088$ & $7.980 \pm 0.116$ & $0.6155 \pm 0.016$ & $2.114 \pm 0.055$ \\
\hline Weight-matched wtM & $13.57 \pm 0.128$ & $7.890 \pm 0.028$ & $6.341 \pm 0.211$ & $0.4314 \pm 0.011$ & $2.536 \pm 0.057$ \\
\hline
\end{tabular}

Values are means \pm SE. $* P<0.0001$ compared with age-matched wild-type males. $\dagger P<0.0001$ compared with weight-matched wild-type males. 
Table 4. Overview of absolute organ weights and organ-tobody weight ratios in wild-type and L314 transgenic male mice

\begin{tabular}{lccc}
\hline \hline & 14-wk $L 314$ Male & 14-wk wtM & Weight-Matched wtM \\
\hline Body weight & $16.51 \pm 0.33$ & $29.58 \pm 0.74$ & $16.82 \pm 0.22$ \\
Brain & $312.7 \pm 5.9$ & $420.0 \pm 1.3$ & $434.2 \pm 6.1$ \\
\%Body weight & $1.9 \pm 0.06^{* \dagger}$ & $1.42 \pm 0.02$ & $2.58 \pm 0.04$ \\
Spleen & $46.25 \pm 3.1$ & $11.53 \pm 1.8$ & $11.54 \pm 7.5$ \\
\%Body weight & $0.28 \pm 0.02^{* \dagger}$ & $0.39 \pm 0.07$ & $0.68 \pm 0.04$ \\
Kidney & $382.8 \pm 1.2$ & $505.5 \pm 2.5$ & $257.0 \pm 6.4$ \\
\%Body weight & $2.32 \pm 0.06^{* \dagger}$ & $1.71 \pm 0.06$ & $1.53 \pm 0.04$ \\
Lung & $140.0 \pm 5.2$ & $204.1 \pm 8.5$ & $158.3 \pm 7.6$ \\
\%Body weight & $0.85 \pm 0.03^{*}$ & $0.69 \pm 0.02$ & $0.94 \pm 0.05$ \\
Liver & $1,112.0 \pm 24.3$ & $1,494.0 \pm 44.5$ & $987.0 \pm 39.4$ \\
\%Body weight & $6.74 \pm 0.09^{* \dagger}$ & $5.06 \pm 0.14$ & $5.86 \pm 0.18$ \\
Heart & $118.4 \pm 2.5$ & $174.6 \pm 7.7$ & $110.9 \pm 4.2$ \\
\%Body weight & $0.72 \pm 0.02^{*}$ & $0.59 \pm 0.03$ & $0.66 \pm 0.02$ \\
Testes (wet) & $141.8 \pm 5.2$ & $148.0 \pm 9.3$ & $78.7 \pm 4.8$ \\
\%Body weight & $0.86 \pm 0.03^{* \dagger}$ & $0.50 \pm 0.03$ & $0.47 \pm 0.03$ \\
Viscera & $2.560 \pm 0.12$ & $3.916 \pm 0.20$ & $2.219 \pm 0.07$ \\
\%Body weight & $15.45 \pm 0.49^{* \dagger}$ & $13.21 \pm 0.54$ & $13.18 \pm 0.30$ \\
Carcass & $11.41 \pm 0.20$ & $22.26 \pm 0.55$ & $12.02 \pm 0.13$ \\
\%Body weight & $69.18 \pm 0.47^{* \dagger}$ & $75.26 \pm 0.25$ & $71.47 \pm 0.50$ \\
\hline
\end{tabular}

\begin{tabular}{lcccc}
\hline & \multicolumn{4}{c}{ 12-wk Muscle Weights as \%Body weight } \\
\cline { 2 - 5 } & $\mathrm{TgM}$ & $\mathrm{wtM}$ & $\mathrm{TgF}$ & $\mathrm{wtF}$ \\
\hline $\begin{array}{c}\text { Anterior muscle } \\
\text { group }\end{array}$ & $0.1744 \pm 0.010 \ddagger$ & $0.2076 \pm 0.012$ & $0.1939 \pm 0.015 \S$ & $0.2834 \pm 0.013$ \\
$\begin{array}{c}\text { Posterior muscle } \\
\text { group }\end{array}$ & $0.4718 \pm 0.011 \S$ & $0.5685 \pm 0.008$ & $0.5005 \pm 0.008 \S$ & $0.5882 \pm 0.012$ \\
& & & &
\end{tabular}

Body, viscera, and carcass weights are means \pm SE in grams, and organ weights are means $\pm \mathrm{SE}$ in milligrams. Values were collected from at least 8 males/group. ${ }^{*} P<0.01$ compared with 14 -wk wtM. $\dagger P<0.01$ compared with 26-day wtM. $\ddagger P<0.05$ and $\S P<0.0001$ compared with the wild-type group.

to distinct differences in the physiological properties of STC-1 and STC-2; however, like STC-1, STC-2 can exert significant developmental effects.

We observed two significant phenotypic consequences of hSTC-2 and hSTC-1 overexpression that were previously unrecognized embryologically based defects: intrauterine growth restriction and developmental delay. hSTC-2 transgene expression was evident by E10.5, when the embryonic circulation was just beginning to function (30) and possibly allowing secreted hSTC-2 to act systemically. The net effect was that transgenic embryos were significantly smaller in weight from E12.5 onward. A similar intrauterine growth-restrictive phenotype was seen in hSTC-1-transgenic embryos. In all of the transgenic lines analyzed for intrauterine growth restriction, we observed a similar degree of weight reduction in E18.5 embryos despite differing levels of transgene expression. This could be indicative of a maximal growth-suppressive effect caused by excess stanniocalcins, such that even higher levels of STCs do not result in further restrictions in growth.

The growth-suppressive effects of hSTC-2 overexpression in utero were maintained and progressed during postnatal life in both sexes of each transgenic line. Unlike other growth retardation mouse mutants, where postnatal catch-up growth is evident, such as in the growth hormone antagonist-transgenic mouse (10), otxl null (1), EGF overexpresser (6), and the STAT3 knock-in phosphorylation mutant (42), hSTC-2-transgenic mouse growth retardation became more severe with age, progressing from an $\sim 25 \%$ reduction in body weight at $P 1$ to $\sim 42 \%$ at $P 45$. The pattern of weight gain by the hSTC-2

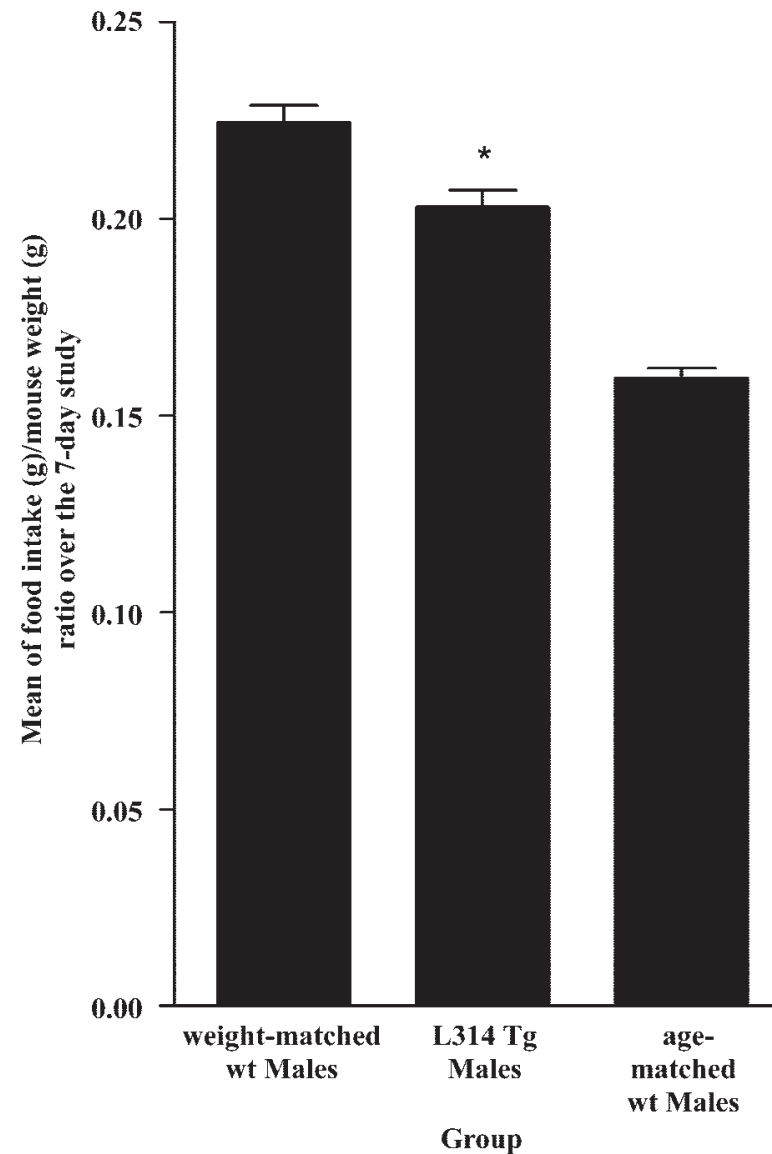

Fig. 7. hSTC-2-transgenic mice exhibit increased food intake. Calculating the amount of food consumed as \%body weight over the 7-day study showed that hSTC-2 transgenics consume more food (22\%) than age-matched wild types and less food $(17 \%)$ than the younger, weight-matched, wild-type mice.

transgenics also differed, most notably over the prepubertal weaning period, where the wild types of both sexes showed an increase in weight gain over the period $P 17-P 21$ and transgenics did not. This may be indicative of a developmental delay whereby the transgenics were unable to derive adequate nutrition or feed appropriately from solid mouse chow due to a metabolic problem or a behavioral defect. Another developmental anomaly was apparent from $P 25$ onward, a time period that is characterized by a well-documented growth hormonedependent pubertal growth spurt $(23,25)$. The wild-type mice exhibited this growth peak at $P 30$, whereas the transgenic growth peak was at $P 45$. This growth pattern lends further support to the possibility that hSTC-2 overexpression results in developmental delay that is manifested and during gonadal maturation.

Table 5. Body content analysis by DEXA

\begin{tabular}{|c|c|c|c|c|}
\hline & \multicolumn{2}{|c|}{$\%$ Lean Mass } & \multicolumn{2}{|c|}{$\%$ Fat Mass } \\
\hline & Male & Female & Male & Female \\
\hline L314 Tg & $80.82 \pm 0.70(7)$ & $75.29 \pm 0.77(8)$ & $19.17 \pm 0.67(7)$ & $24.78 \pm 0.75$ \\
\hline
\end{tabular}
Wild type $\quad 83.33 \pm 1.14(8) \quad 76.92 \pm 0.81(8) \quad 16.74 \pm 1.14(8) \quad 22.99 \pm 0.81(8)$

$\%$ Lean mass and \%fat mass values are means $\pm \mathrm{SE}$; values in parentheses are nos. of mice analyzed. 
A
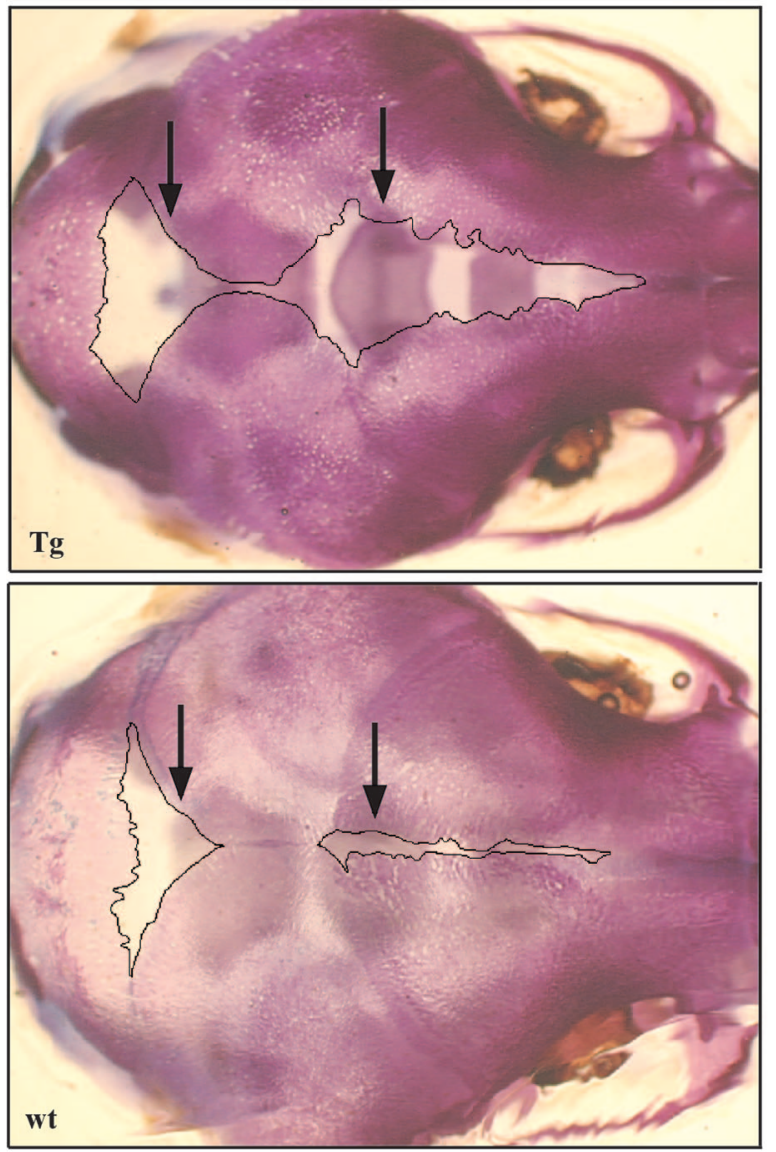

B

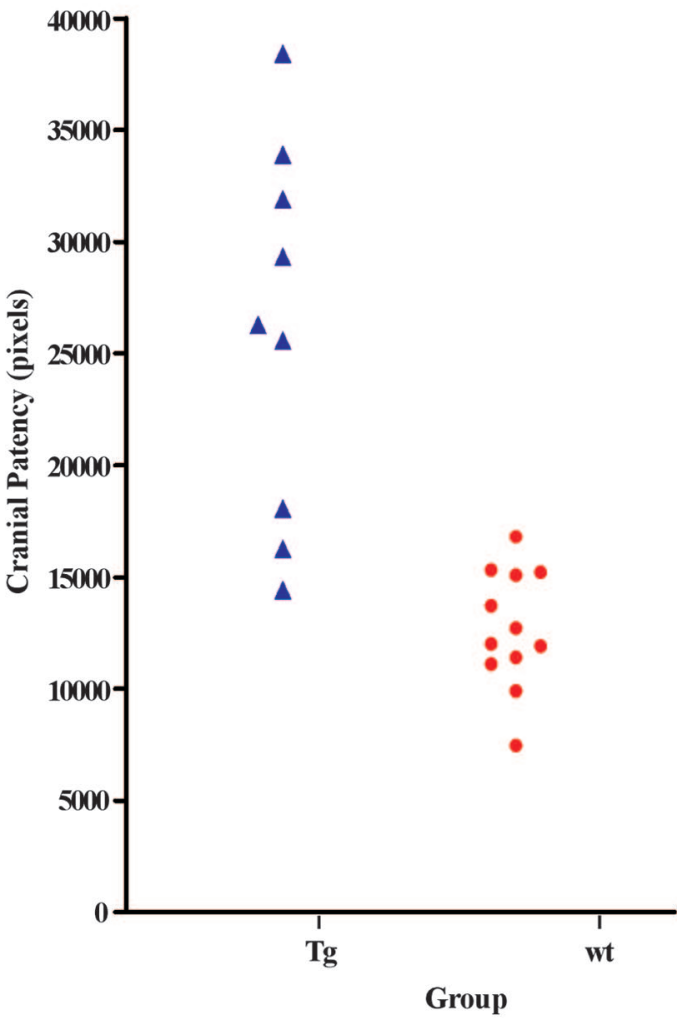

C

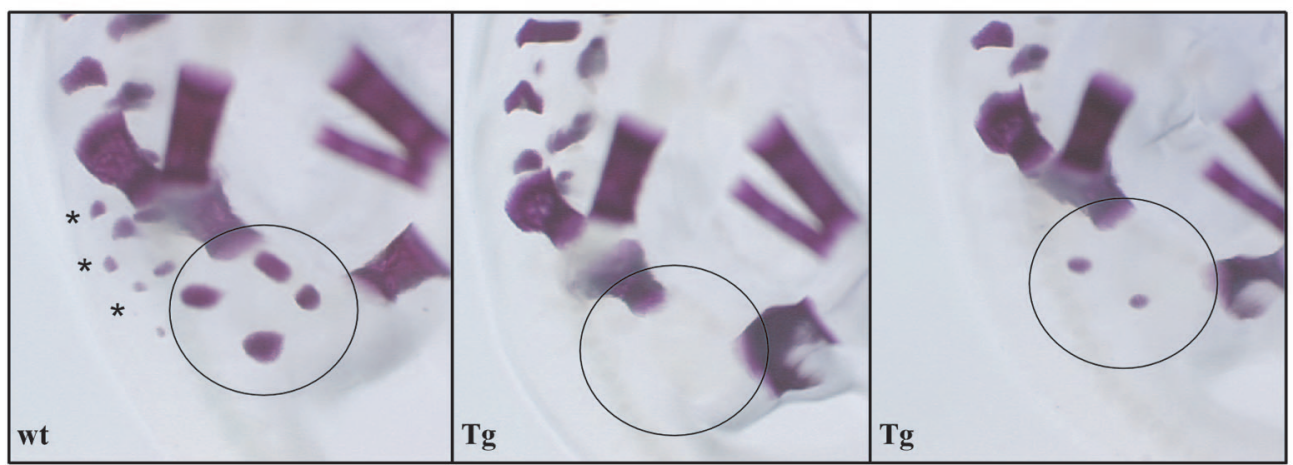

Fig. 8. Cranial patency and endochondral ossification. Delay in bone formation exhibited by the hSTC-2-transgenic mice. A: Alizarin red- and Alcian blue-stained hSTC-2 postnatal day 1 skulls revealed a reduction in the amount of bone formation in the transgenic skull (arrows). The space between the wild-type posterior frontal and sagittal sutures is very narrow compared with that found in transgenic mice (black outline). $B$ : pixel area of the space between the edges of the skull bones in the transgenics $(\mathbf{\Delta})$ is more than twice that of wild-type mice $(\bullet)$. C: stained E16.5 wild-type and transgenic embryos from the same litter. $\star$ Difference in ossification (red stain) of hip bones (within black circle) and vertebrae.

We also examined embryos and neonates for gross morphological indications of developmental delay. The most significant observation related to this is the degree of skull patency in hSTC-2-transgenic pups that in some respects resembles cleidocranial dysplasia (58). This intramembranous bone phenotype was reminiscent of the sagittal and parietal foramen observed in $m s \times 2$ null mice $(19,40)$, mice homozygous for the hypomorphic $c b f b^{G F P}$ allele (21), and mice in which the bonemorphogenic protein antagonist noggin has been applied to the developing cranium (56). In all of these mutant mouse models, the degree of patency along the sagittal and parietal suture lines is significantly greater than in wild-type littermates. Filvaroff et al. (13) found that the cranial suture lines in their adult hSTC-1-transgenic mice were morphologically distinct, and TRAP staining suggested increased osteoclast activity along the cranial suture lines. Interestingly, they also showed that hSTC-1 overexpression decreased the rate at which bone mineralization occurred (13). Collectively, these data point to 
Table 6. Serum calcium, phosphate, and alkaline phosphatase levels in hSTC-2-transgenic and wild-type mice

\begin{tabular}{cccc}
\hline \hline & Calcium, mmol/ & Phosphate, $\mathrm{mmol} / \mathrm{l}$ & Alkaline Phosphatase, $\mathrm{U} / \mathrm{l}$ \\
\hline L314 & & & \\
wtM & $2.836 \pm 0.030$ & $3.323 \pm 0.079$ & $132.1 \pm 7.203$ \\
TgM & $2.849 \pm 0.044$ & $3.311 \pm 0.126$ & $107.5 \pm 3.612^{*}$ \\
wtF & $2.840 \pm 0.027$ & $3.141 \pm 0.068$ & $159.7 \pm 6.977$ \\
TgF & $2.765 \pm 0.021^{*}$ & $3.347 \pm 0.013$ & $133.9 \pm 7.974 *$ \\
L372 & & & \\
wtM & $2.796 \pm 0.029$ & $3.406 \pm 0.111$ & $122.6 \pm 8.752$ \\
TgM & $2.769 \pm 0.035$ & $3.457 \pm 0.073$ & $108.9 \pm 8.221$ \\
wtF & $2.759 \pm 0.029$ & $3.232 \pm 0.01$ & $132.1 \pm 6.579$ \\
TgF & $2.678 \pm 0.027$ & $3.481 \pm 0.078$ & $144.8 \pm 11.77$ \\
\hline
\end{tabular}

Values represent means \pm SE of $10-15$ mice with multiple parameters measured from each mouse. ${ }^{*} P<0.05$ compared with sex-matched wild types of the same line.

developmental delay caused by a decreased rate of bone formation due to the overexpression of either hSTC-1 or hSTC-2. In support of this, our hSTC-2-transgenic embryos showed delayed ossification in different endochondral skeletal elements. Interestingly, these results would not have been predicted on the basis of the recent report from Yoshiko et al. (59) showing that, in vitro, STC-1 actually augments the differentiation of mature rat calvaria osteoblasts shown by the enhanced expression of the osteoblast markers. Therefore, the delayed bone development we report here may result from systemic exposure to hSTC- 1 or hSTC- 2 that may alter early signaling pathways necessary for the normal temporal development of bone and proliferation of osteoprogenitors. Further studies are currently underway to investigate the mechanism by which hSTC-1 and -2 exert their effect on bone development. Obviously, this contributed to the severe postnatal growth restriction seen in our hSTC-1 and hSTC-2-transgenic mice. However, our data also show that growth retardation occurs early in development, before significant bone ossification begins. Therefore, the growth-restrictive properties of STC-1 and STC-2 likely impact other earlier developmental processes and/or cell types.

To begin assessing these possibilities, we performed a series of growth studies with E14.5 MEFs from hSTC-1 and wildtype embryos, because the proliferation rate of MEFs from mouse mutants that exhibit embryonic growth restriction have been successfully replicated in vitro $(47,55,57)$. However, experiments with hSTC-1 MEFs did not mimic the growthrestrictive phenotype seen in vivo. Results similar to ours were obtained using MEFs prepared from p57Kip2-deficient mice that also exhibit skeletal abnormalities and growth retardation (44) and with MEFs from $c d k 4$ null mice that display growth retardation to the same extent as our transgenic mice (48). The lack of a proliferation defect in hSTC-1-transgenic MEFs suggests that the reduced-growth phenotype is restricted to a different tissue compartment during development and that these effects are cumulative, causing a progressive and proportional reduction in embryo mass.

Many mouse mutants exhibiting a dwarf phenotype are the result of disrupted signaling of the GH/IGF pathway $(9,15,25$, 36). Changes in the levels of GH/IGF signaling components can also occur secondary to the primary mutation and result in growth restriction $(3,14,20,22)$. However, as in the case of hSTC-1 overexpression (49), we did not detect changes in GH/IGF signaling in response to hSTC-2 overexpression, leading us to conclude that intrauterine and postnatal growth retardation occurred independently of this pathway. Clearly, our data indicate that an intact IGF-I signaling system
A
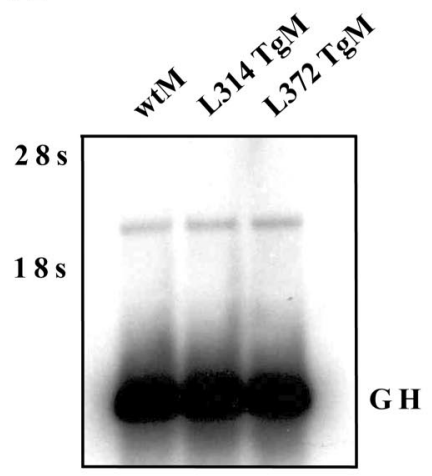

$\mathbf{C}$

E 14.5 E 16.5 E 18.5

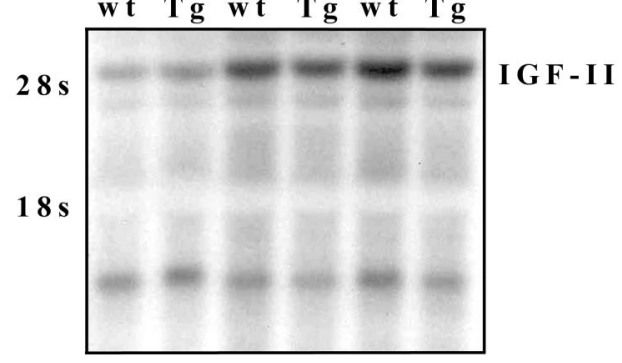

B

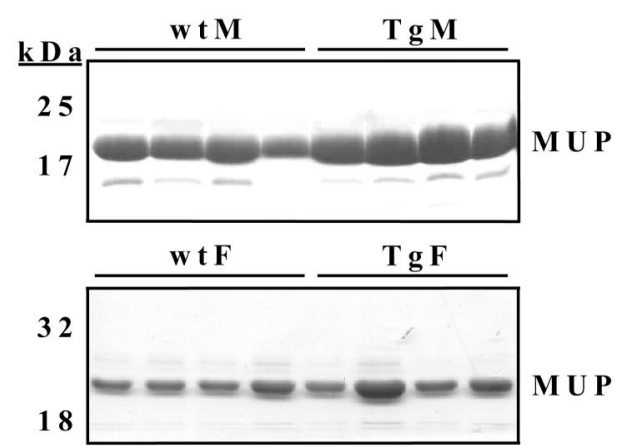

D

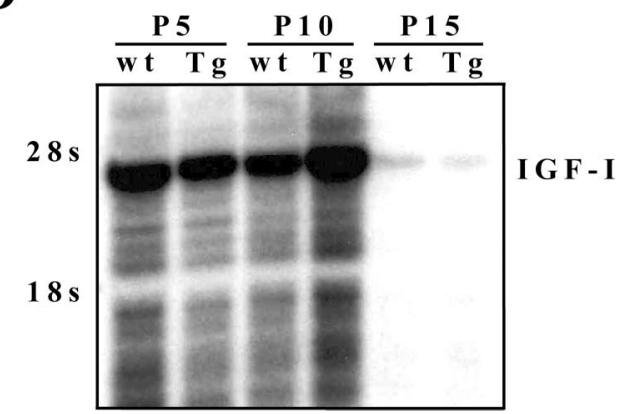

Fig. 9. Assessment of the somatomedin pathway. A: growth hormone $(\mathrm{GH})$ mRNA expression was analyzed by Northern blot using $5 \mu \mathrm{g}$ of pooled total pituitary RNA, and steady-state mRNA levels were not different between wild types (wtM) and transgenics $(\mathrm{TgM})$ or both lines. $B$ : downstream GH signaling was assessed by Coomassiestained SDS-PAGE of transgenic and wildtype urine for major urinary protein (MUP). The level of MUP was not decreased in the transgenics compared with wild types in both sexes. C: embryonic IGF-II mRNA expression, determined by Northern blotting of whole embryo total RNA $(30 \mu \mathrm{g})$, showed no difference in its expression between transgenics and wild types. $D$ : postnatal IGF-I Northern analysis also showed no observable difference in expression levels in liver total RNA $(30 \mu \mathrm{g})$. 
cannot counteract the effects of excess circulating levels of hSTC-2.

Recently, McCudden et al. (29) showed that STC-1 and its receptor can localize to mitochondria in a variety of tissues and that STC-1 can increase the respiration rate of isolated liver mitochondria in vitro. It is possible that constitutively elevated hSTC-2 resulted in altered metabolism and that this had a contributing effect on the growth-restrictive phenotype. Food consumption by the hSTC-2-transgenic mice was $22 \%$ greater than age-matched wild-type mice. Filvaroff et al. (13) also found a comparable increase in food intake along with a $10 \%$ increase in oxygen consumption in their hSTC-1-transgenic mice. Obviously, hyperphagia, in combination with increased oxygen requirement, is highly suggestive of a metabolic defect and appears to be a hallmark of excess circulating hSTC-1 or hSTC-2. Hyperphagia has been documented in a number of growth-restricted mouse mutants and is usually associated with aberrant expression or signaling of proteins that regulate various aspects of metabolism, including GH (10), melanocortin-1 and -4 receptors $(17,27)$, and fibroblast growth factor-19 (46). These data are consistent with a role for stanniocalcins in controlling certain aspects of metabolism.

On the basis of the data presented here, we propose that the stanniocalcins represent a new class of trophic factors that play a role in growth regulation independently of the GH/IGF axis. When present in supraphysiological levels, stanniocalcins cause developmental delay, especially in intramembranous bone. Our findings to date, along with those of Yoshiko et al. (59), advocate a role for stanniocalcins in regulating bone development. The fact that hSTC-2 overexpression is lethal to a proportion of neonates implies that this hormone has deleterious effects on mammalian development that are linked to cell proliferation and differentiation. The precise mechanism by which stanniocalcins reduce growth and cause death is critical to our understanding of their importance in mammalian physiology, and it appears that tissue-specific effects on cellular metabolism may be key to their mechanism of action.

\section{ACKNOWLEDGMENTS}

We thank Dr. Chris Pin for critical reading and constructive comments on the manuscript.

\section{GRANTS}

This research was supported by an operating grant to G. E. DiMattia from the Canadian Institutes of Health Research (CIHR) and a grant from the Lawson Health Research Institute Internal Research Fund. A. D. Gagliardi was supported by a student fellowship from the CIHR Strategic Training Program in Cancer Research and Technology Transfer.

\section{REFERENCES}

1. Acampora D, Mazan S, Tuorto F, Avantaggiato V, Tremblay JJ, Lazzaro D, di Carlo A, Mariano A, Macchia PE, Corte G, Macchia V, Drouin J, Brulet $\mathbf{P}$, and Simeone A. Transient dwarfism and hypogonadism in mice lacking Otx1 reveal prepubescent stage-specific control of pituitary levels of GH, FSH and LH. Development 125: 1229-1239, 1998.

2. Al-Shawi R, Wallace H, Harrison S, Jones C, Johnson D, and Bishop JO. Sexual dimorphism and growth hormone regulation of a hybrid gene in transgenic mice. Mol Endocrinol 6: 181-190, 1992.

3. Bessone S, Vidal F, Le Bouc Y, Epelbaum J, Bluet-Pajot MT, and Darmon M. EMK protein kinase-null mice: dwarfism and hypofertility associated with alterations in the somatotrope and prolactin pathways. Dev Biol 214: 87-101, 1999.

4. Bialek P, Chan CT, and Yee SP. Characterization of a novel insertional mouse mutation, kkt: a closely linked modifier of Pax1. Dev Biol 218: 354-366, 2000.
5. Binkley N, Dahl DB, Engelke J, Kawahara-Baccus T, Krueger D, and Colman RJ. Bone loss detection in rats using a mouse densitometer. J Bone Miner Res 18: 370-375, 2003.

6. Chan SY and Wong RW. Expression of epidermal growth factor in transgenic mice causes growth retardation. J Biol Chem 275: $38693-$ 38698, 2000.

7. Chang AC, Jellinek DA, and Reddel RR. Mammalian stanniocalcins and cancer. Endocr Relat Cancer 10: 359-373, 2003.

8. Chang AC and Reddel RR. Identification of a second stanniocalcin cDNA in mouse and human: stanniocalcin 2. Mol Cell Endocrinol 141: 95-99, 1998.

9. Constancia M, Hemberger M, Hughes J, Dean W, Ferguson-Smith A, Fundele R, Stewart F, Kelsey G, Fowden A, Sibley C, and Reik W. Placental-specific IGF-II is a major modulator of placental and fetal growth. Nature 417: 945-948, 2002.

10. Coschigano KT, Holland AN, Riders ME, List EO, Flyvbjerg A, and Kopchick JJ. Deletion, but not antagonism, of the mouse growth hormone receptor results in severely decreased body weights, insulin, and insulinlike growth factor I levels and increased life span. Endocrinology 144: 3799-3810, 2003.

11. Deol HK, Varghese R, Wagner GF, and DiMattia GE. Dynamic regulation of mouse ovarian stanniocalcin expression during gestation and lactation. Endocrinology 141: 3412-3421, 2000.

12. DiMattia GE, Varghese R, and Wagner GF. Molecular cloning and characterization of stanniocalcin-related protein. Mol Cell Endocrinol 146: 137-140, 1998.

13. Filvaroff EH, Guillet S, Zlot C, Bao M, Ingle G, Steinmetz H, Hoeffel J, Bunting S, Ross J, Carano RA, Powell-Braxton L, Wagner GF, Eckert R, Gerritsen ME, and French DM. Stanniocalcin 1 alters muscle and bone structure and function in transgenic mice. Endocrinology 143: 3681-3690, 2002.

14. Foucher I, Volovitch M, Frain M, Kim JJ, Souberbielle JC, Gan L, Unterman TG, Prochiantz A, and Trembleau A. Hoxa5 overexpression correlates with IGFBP1 upregulation and postnatal dwarfism: evidence for an interaction between Hoxa5 and Forkhead box transcription factors. Development 129: 4065-4074, 2002.

15. Holzenberger M, Leneuve P, Hamard G, Ducos B, Perin L, Binoux M, and Le Bouc Y. A targeted partial invalidation of the insulin-like growth factor I receptor gene in mice causes a postnatal growth deficit. Endocrinology 141: 2557-2566, 2000.

16. Hurford RK Jr, Cobrinik D, Lee MH, and Dyson N. pRB and p107/p130 are required for the regulated expression of different sets of E2F responsive genes. Genes Dev 11: 1447-1463, 1997.

17. Huszar D, Lynch CA, Fairchild-Huntress V, Dunmore JH, Fang Q, Berkemeier LR, Gu W, Kesterson RA, Boston BA, Cone RD, Smith FJ, Campfield LA, Burn P, and Lee F. Targeted disruption of the melanocortin-4 receptor results in obesity in mice. Cell 88: 131-141, 1997.

18. Ishibashi K, Miyamoto K, Taketani Y, Morita K, Takeda E, Sasaki S, and Imai M. Molecular cloning of a second human stanniocalcin homologue (STC2). Biochem Biophys Res Commun 250: 252-258, 1998.

19. Ishii M, Merrill AE, Chan YS, Gitelman I, Rice DP, Sucov HM, and Maxson RE Jr. Msx2 and Twist cooperatively control the development of the neural crest-derived skeletogenic mesenchyme of the murine skull vault. Development 130: 6131-6142, 2003.

20. Jellinek DA, Chang AC, Larsen MR, Wang X, Robinson PJ, and Reddel RR. Stanniocalcin 1 and 2 are secreted as phosphoproteins from human fibrosarcoma cells. Biochem J 350: 453-461, 2000.

21. Kundu M, Javed A, Jeon JP, Horner A, Shum L, Eckhaus M, Muenke M, Lian JB, Yang Y, Nuckolls GH, Stein GS, and Liu PP. Cbf $\beta$ interacts with Runx 2 and has a critical role in bone development. Nat Genet 32: 639-644, 2002.

22. Li Y, Iida K, O'Neil J, Zhang P, Li S, Frank A, Gabai A, Zambito F, Liang SH, Rosen CJ, and Cavener DR. PERK eIF2 $\alpha$ kinase regulates neonatal growth by controlling the expression of circulating insulin-like growth factor-I derived from the liver. Endocrinology 144: 3505-3513, 2003

23. Liu JL and LeRoith D. Insulin-like growth factor I is essential for postnatal growth in response to growth hormone. Endocrinology 140: 5178-5184, 1999.

24. Luo CW, Kawamura K, Klein C, and Hsueh AJ. Paracrine regulation of ovarian granulosa cell differentiation by stanniocalcin (STC) 1: mediation through specific STC1 receptors. Mol Endocrinol 18: 2085-2096, 2004. 
25. Lupu F, Terwilliger JD, Lee K, Segre GV, and Efstratiadis A. Roles of growth hormone and insulin-like growth factor 1 in mouse postnatal growth. Dev Biol 229: 141-162, 2001.

26. Madsen KL, Tavernini MM, Yachimec C, Mendrick DL, Alfonso PJ, Buergin M, Olsen HS, Antonaccio MJ, Thomson AB, and Fedorak RN. Stanniocalcin: a novel protein regulating calcium and phosphate transport across mammalian intestine. Am J Physiol Gastrointest Liver Physiol 274: G96-G102, 1998.

27. Marsh DJ, Weingarth DT, Novi DE, Chen HY, Trumbauer ME, Chen AS, Guan XM, Jiang MM, Feng Y, Camacho RE, Shen Z, Frazier EG, Yu H, Metzger JM, Kuca SJ, Shearman LP, Gopal-Truter S, MacNeil DJ, Strack AM, MacIntyre DE, Van der Ploeg LH, and Qian S. Melanin-concentrating hormone 1 receptor-deficient mice are lean, hyperactive, and hyperphagic and have altered metabolism. Proc Natl Acad Sci USA 99: 3240-3245, 2002.

28. Martin JF, Bradley A, and Olson EN. The paired-like homeo box gene MHox is required for early events of skeletogenesis in multiple lineages. Genes Dev 9: 1237-1249, 1995.

29. McCudden CR, James KA, Hasilo C, and Wagner GF. Characterization of mammalian stanniocalcin receptors. Mitochondrial targeting of ligand and receptor for regulation of cellular metabolism. J Biol Chem 277: 45249-45258, 2002.

30. McGrath KE, Koniski AD, Malik J, and Palis J. Circulation is established in a stepwise pattern in the mammalian embryo. Blood 101: 1669-1676, 2003

31. Metcalf D, Greenhalgh CJ, Viney E, Willson TA, Starr R, Nicola NA, Hilton DJ, and Alexander WS. Gigantism in mice lacking suppressor of cytokine signalling-2. Nature 405: 1069-1073, 2000.

32. Moore EE, Kuestner RE, Conklin DC, Whitmore TE, Downey W, Buddle MM, Adams RL, Bell LA, Thompson DL, Wolf A, Chen L, Stamm MR, Grant FJ, Lok S, Ren H, and De Jongh KS. Stanniocalcin 2: characterization of the protein and its localization to human pancreatic alpha cells. Horm Metab Res 31: 406-414, 1999.

33. Nagy TR, Prince CW, and Li J. Validation of peripheral dual-energy $\mathrm{X}$-ray absorptiometry for the measurement of bone mineral in intact and excised long bones of rats. J Bone Miner Res 16: 1682-1687, 2001.

34. Niwa H, Yamamura K, and Miyazaki J. Efficient selection for highexpression transfectants with a novel eukaryotic vector. Gene 108: 193199, 1991.

35. Norstedt G and Palmiter R. Secretory rhythm of growth hormone regulates sexual differentiation of mouse liver. Cell 36: 805-812, 1984.

36. Okada $\mathbf{S}$ and Kopchick JJ. Biological effects of growth hormone and its antagonist. Trends Mol Med 7: 126-132, 2001.

37. Olsen HS, Cepeda MA, Zhang QQ, Rosen CA, and Vozzolo BL. Human stanniocalcin: a possible hormonal regulator of mineral metabolism. Proc Natl Acad Sci USA 93: 1792-1796, 1996.

38. Paciga M, McCudden CR, Londos C, DiMattia GE, and Wagner GF. Targeting of big stanniocalcin and its receptor to lipid storage droplets of ovarian steroidogenic cells. J Biol Chem 278: 49549-49554, 2003.

39. Pete G, Fuller CR, Oldham JM, Smith DR, D'Ercole AJ, Kahn CR, and Lund PK. Postnatal growth responses to insulin-like growth factor I in insulin receptor substrate-1-deficient mice. Endocrinology 140: 5478 5487, 1999.

40. Satokata I, Ma L, Ohshima H, Bei M, Woo I, Nishizawa K, Maeda T, Takano Y, Uchiyama M, Heaney S, Peters H, Tang Z, Maxson R, and Maas R. Msx2 deficiency in mice causes pleiotropic defects in bone growth and ectodermal organ formation. Nat Genet 24: 391-395, 2000.

41. Sheikh-Hamad D, Bick R, Wu GY, Christensen BM, Razeghi P, Poindexter B, Taegtmeyer H, Wamsley A, Padda R, Entman M, Nielsen S, and Youker K. Stanniocalcin-1 is a naturally occurring L-channel inhibitor in cardiomyocytes: relevance to human heart failure. Am J Physiol Heart Circ Physiol 285: H442-H448, 2003.

42. Shen Y, Schlessinger K, Zhu X, Meffre E, Quimby F, Levy DE, and Darnell JE Jr. Essential role of STAT3 in postnatal survival and growth revealed by mice lacking STAT3 serine 727 phosphorylation. Mol Cell Biol 24: 407-419, 2004.

43. Sjogren K, Bohlooly YM, Olsson B, Coschigano K, Tornell J, Mohan S, Isaksson OG, Baumann G, Kopchick J, and Ohlsson C. Dispropor- tional skeletal growth and markedly decreased bone mineral content in growth hormone receptor -/- mice. Biochem Biophys Res Commun 267: 603-608, 2000.

44. Takahashi K, Nakayama K, and Nakayama K. Mice lacking a CDK inhibitor, p57Kip2, exhibit skeletal abnormalities and growth retardation. J Biochem (Tokyo) 127: 73-83, 2000.

45. Tansey JT, Sztalryd C, Gruia-Gray J, Roush DL, Zee JV, Gavrilova O, Reitman ML, Deng CX, Li C, Kimmel AR, and Londos C. Perilipin ablation results in a lean mouse with aberrant adipocyte lipolysis, enhanced leptin production, and resistance to diet-induced obesity. Proc Natl Acad Sci USA 98: 6494-6499, 2001.

46. Tomlinson E, Fu L, John L, Hultgren B, Huang X, Renz M, Stephan JP, Tsai SP, Powell-Braxton L, French D, and Stewart TA. Transgenic mice expressing human fibroblast growth factor-19 display increased metabolic rate and decreased adiposity. Endocrinology 143: 1741-1747, 2002

47. Trumpp A, Refaeli Y, Oskarsson T, Gasser S, Murphy M, Martin GR, and Bishop JM. c-Myc regulates mammalian body size by controlling cell number but not cell size. Nature 414: 768-773, 2001.

48. Tsutsui T, Hesabi B, Moons DS, Pandolfi PP, Hansel KS, Koff A, and Kiyokawa H. Targeted disruption of CDK4 delays cell cycle entry with enhanced p27(Kip1) activity. Mol Cell Biol 19: 7011-7019, 1999.

49. Varghese R, Gagliardi AD, Bialek PE, Yee SP, Wagner GF, and DiMattia GE. Overexpression of human stanniocalcin affects growth and reproduction in transgenic mice. Endocrinology 143: 868-876, 2002.

50. Varghese R, Wong CK, Deol H, Wagner GF, and DiMattia GE. Comparative analysis of mammalian stanniocalcin genes. Endocrinology 139: 4714-4725, 1998.

51. Wagner GF. Stanniocalcin: Structure, Function and Regulation. Amsterdam: Elsevier Science, 1994.

52. Wagner GF, Vozzolo BL, Jaworski E, Haddad M, Kline RL, Olsen HS, Rosen CA, Davidson MB, and Renfro JL. Human stanniocalcin inhibits renal phosphate excretion in the rat. J Bone Miner Res 12: 165-171, 1997.

53. Wallenius K, Sjogren K, Peng XD, Park S, Wallenius V, Liu JL, Umaerus M, Wennbo H, Isaksson O, Frohman L, Kineman R, Ohlsson C, and Jansson JO. Liver-derived IGF-I regulates GH secretion at the pituitary level in mice. Endocrinology 142: 4762-4770, 2001

54. Wang J, Niu W, Nikiforov Y, Naito S, Chernausek S, Witte D, LeRoith D, Strauch A, and Fagin JA. Targeted overexpression of IGF-I evokes distinct patterns of organ remodeling in smooth muscle cell tissue beds of transgenic mice. J Clin Invest 100: 1425-1439, 1997.

55. Wang Z, Rose DW, Hermanson O, Liu F, Herman T, Wu W, Szeto D, Gleiberman A, Krones A, Pratt K, Rosenfeld R, Glass CK, and Rosenfeld MG. Regulation of somatic growth by the p160 coactivator p/CIP. Proc Natl Acad Sci USA 97: 13549-13554, 2000.

56. Warren SM, Brunet LJ, Harland RM, Economides AN, and Longaker MT. The BMP antagonist noggin regulates cranial suture fusion. Nature 422: 625-629, 2003

57. Yang S, Cho YS, Chennathukuzhi VM, Underkoffler LA, Loomes K, and Hecht NB. Translin-associated factor $\mathrm{X}$ is post-transcriptionally regulated by its partner protein TB-RBP, and both are essential for normal cell proliferation. J Biol Chem 279: 12605-12614, 2004.

58. Yoshida CA, Furuichi T, Fujita T, Fukuyama R, Kanatani N, Kobayashi S, Satake M, Takada K, and Komori T. Core-binding factor beta interacts with Runx 2 and is required for skeletal development. Nat Genet 32: 633-638, 2002.

59. Yoshiko Y, Maeda N, and Aubin JE. Stanniocalcin 1 stimulates osteoblast differentiation in rat calvaria cell cultures. Endocrinology 144: 4134-4143, 2003.

60. Zhang J, Alfonso P, Thotakura NR, Su J, Buergin M, Parmelee D, Collins AW, Oelkuct M, Gaffney S, Gentz S, Radman DP, Wagner GF, and Gentz R. Expression, purification, and bioassay of human stanniocalcin from baculovirus-infected insect cells and recombinant $\mathrm{CHO}$ cells. Protein Expr Purif 12: 390-398, 1998.

61. Zhang K, Lindsberg PJ, Tatlisumak T, Kaste M, Olsen HS, and Andersson LC. Stanniocalcin: a molecular guard of neurons during cerebral ischemia. Proc Natl Acad Sci USA 97: 3637-3642, 2000. 